The following document is a pre-print version of:

Ross, P.-S., White, J.D.L., Zimanowski, B. et Buttner, R. (2008) Rapid injection of particles and gas into non-fluidized

granular material, and some volcanological implications. Bulletin of Volcanology 70: 1151-1168

\title{
Rapid injection of particles and gas into non-fluidized granular material, and some volcanological implications
}

\author{
Pierre-Simon Ross ${ }^{1}$, James D.L. White ${ }^{1}$, Bernd Zimanowski ${ }^{2}$, Ralf Büttner ${ }^{2}$ \\ 1. Department of Geology, University of Otago, PO Box 56, Dunedin, New Zealand \\ 2. Physikalisch-Vulkanologisches Labor, Universität Würzburg, Pleicherwall 1, D-97070 Würzburg, Germany \\ * Corresponding author. \\ Now at: INRS-ETE, 490 rue de la Couronne, Québec (Qc), Canada, G1K 9A9
}

Email addresses: rossps@ete.inrs.ca (P.-S. Ross); james.white@otago.ac.nz (J.D.L. White); zimano@mail.uniwuerzburg.de (B. Zimanowski); buettner@geologie.uni-wuerzburg.de (R. Büttner)

\begin{abstract}
In diatremes and other volcanic vents, steep bodies of volcaniclastic material having differing properties (particle size distribution, proportion of lithic fragments, etc.) from those of the surrounding vent-filling volcaniclastic material are often found. It has been proposed that cylindrical or cone-shaped bodies result from the passage of "debris jets" generated after phreatomagmatic explosions or other discrete subterranean bursts. To learn more about such phenomena, we model experimentally the injection of gas-particulate dispersions through other particles. Analogue materials (glass beads or sand) and a finite amount of compressed air are used in the laboratory. The gas is made available by rapidly opening a valve therefore the injection of gas and coloured particles into a granular host is a brief $(<1 \mathrm{~s})$, discrete event, comparable to what occurs in nature following subterranean explosions. The injection assumes a bubble shape while expanding and propagating upwards. In reaction, the upper part of the clastic host moves upward and outward above the 'bubble', forming a 'dome'. The doming effect is much more pronounced for shallow injection depths (thin hosts), with dome angles reaching more than $45^{\circ}$. Significant surface doming is also observed for some full-scale subterranean blasts (e.g. buried nuclear explosions), so it is not an artefact of our setup. What happens next in the experiments depends on the depth of injection and the nature of the host material. With shallow injection into a permeable host (glass beads), the compressed air in the "bubble' is able to diffuse rapidly through the roof. Meanwhile the coloured beads sediment into the transient cavity, which is also closing laterally because of inward-directed granular flow of the host. Depending on the initial gas pressure in the reservoir, the two-phase flow can "erupt" or not; non-erupting injections produce cylindrical bodies of coloured beads whereas erupting runs produce flaring upward or conical deposits. Changing the particle size of the host glass beads does not have a large effect under the size range investigated (100-200 to 300-400 $\mu \mathrm{m})$. Doubling the host thickness (injection depth) requires a doubling of the initial gas pressure to produce similar phenomena. Such injections - whether erupting or wholly subterranean - provide a compelling explanation for the origin and characteristics of multiple cross-cutting bodies that have been documented for diatreme and other vent deposits.
\end{abstract}

Keywords Debris jets, Diatremes, Phreatomagmatism, Experimental volcanology, Gas-particle flow, Explosions, Granular material

\section{Introduction}

When explosives are detonated underground, rock is vaporized and large quantities of gas are produced and rapidly expand. If the surrounding material consists of loose debris then it will be readily moved by the expanding gas. In explosion cratering, scaled depth is often defined as the depth of burial of the explosive charge (in metres) divided by the cube-root of the liberated energy (in Joules) (resulting units: $\mathrm{m} / \mathrm{J}^{1 / 3}$ ) (e.g., Goto et al. 2001). Empirically, the shapes of explosion clouds produced at the same scaled depth are similar to each other (Ohba et al.
2002). At very shallow scaled depths, explosions in granular materials do not differ a great deal from surface blasts: a relatively large volume of debris is ejected in the explosion cloud, which has a strong horizontal component, and a crater is produced in the confining material (e.g., Carlson and Jones 1965). As the scaled depth increases, the ejection angle will decrease until the cloud becomes comparatively very narrow, more like a jet (Ohba et al. 2002).

Jets of debris are also produced in volcanic settings when discrete explosions occur in the shallow 
subsurface or debris-filled conduit structures. For instance, when magma encounters water, explosive interactions can result, with thermal energy from the magma transferred extremely rapidly to the external water, which flashes to steam and expands explosively (e.g., Wohletz 1986; Zimanowski et al. 1991; Büttner and Zimanowski 1998). Jets resulting from this explosive expansion and entrainment comprise vertically travelling volcaniclastic debris (newly fragmented magma and pre-existing clasts), magmatic gases, and water vapour $+/$ - liquid water that propagate upward toward the ground surface.

It is inferred that the passage of such debris jets through existing vent fills will produce roughly cylindrical or conical bodies of volcaniclastic material having differing properties (particle size distribution, proportion and types of lithic and juvenile fragments) from those of the surrounding debris. Such bodies are observed in eroded volcanoes such as diatremes (e.g., Hearn 1968; White 1991; Fig. 1). Ross and White (2006) described the shape and size of some of these bodies from a vent complex in Antarctica and proposed theoretical end-member possibilities for the behaviour of debris jets travelling through a granular host. The manner in which debris jets propagate through clastic hosts is still poorly constrained, and so is the manner in which debris are deposited from the jet, or following the jet's passage, to produce the roughly cylindrical or conical body. We carried out analogue laboratory experiments to shed some light on these issues. We do not assume that the vent fills of interest are fluidized between eruptive pulses (cf. Woolsey et al 1975; Kokelaar 1983; Walters et al. 2006) so we model the rapid injection of particles and gas into static, non-fluidized granular material.

\section{Methods}

Materials. Natural debris jets involve partiallycondensable gases and poorly sorted debris of various grain shapes and densities. Hot and plastic, perhaps sticky, pyroclasts might be present in natural jets; liquid water is another possibility. We simplify these multiphase transport systems experimentally by using only gas (compressed air) and solid particles (glass beads or sand). The glass beads we utilize are nearly monodisperse (extremely well sorted) and almost spherical. To examine the effect of particle size, we use three classes of white glass beads as host materials: $100-200,200-300$ and $300-400 \mu \mathrm{m}$. The $200-$ $300 \mu \mathrm{m}$ white beads have a bulk density of $1.48 \mathrm{~g} / \mathrm{cm}^{3}$, a porosity of $38 \%$ and an angle of repose of $25^{\circ}$. The blue beads used as horizontal markers in the host and the red beads used as injected material are in the size range 200$300 \mu \mathrm{m}$. Sand, by contrast, is a heterogeneous material (Table 1). Nevertheless, the system exhibits a different behaviour when sand is used, and it might represent a better analogue to vent-filling materials, so it is interesting to compare runs using glass beads with others using sand.

Setup. In most runs, we inject dry red glass beads and compressed air into a dry, non-fluidized, granular host (such as white glass beads). Before the beginning of each run, the red beads are placed into a cylindrical crucible $(4.5 \mathrm{~cm}$ internal diameter, $11.5 \mathrm{~cm}$ internal height) underlying a much larger rectangular container (base 41.0 $x 10.6 \mathrm{~cm}$; Fig. 2). A paper wafer at the base of crucible prevents the red beads from falling into the air pipe and ensures compressed air will not bore a hole through the red beads and form an air jet (the wafer always survives the experiments in perfect shape). The rectangular container is then filled to a predetermined level with granular material. This material represents the debris filling volcanic vents or the earth above other, e.g. man-made, subterranean explosions - and constitutes the 'host' which confines the propagation of the experimental flows. Horizontal lines of blue glass beads are placed against the window at regular intervals in the host, to aid in visualizing flow and deformation.

A critical part of the design is the way we inject the red beads and compressed air into the host (Fig. 2). A burst of pressurized air is released very rapidly (a few ms) at the base of the crucible by opening a high-speed Herion solenoid valve, behind which a fixed volume of compressed air is stored. The response time from switching the voltage to onset of opening is typically 15 $\mathrm{ms}$, complete opening is reached $<10 \mathrm{~ms}$ later.

Once the valve opens, gas expands in the low pressure section of the setup and forces the red beads upwards into the host, initially as a gas-driven plug flow of red beads, but rapidly becoming a two-phase flow of red beads suspended in gas. A variety of phenomena then occurs depending on the injection depth (thickness of granular host) and the initial air pressure in the reservoir.

This method differs considerably from fluidization experiments (e.g., Woolsey et al. 1975; Wilson 1980; Nichols et al. 1994; Walters et al. 2006) in which compressed gas or water - without any suspended particles - is injected from the base of a container at a constant fluid velocity for several seconds or minutes, leading to quasi steady-state conditions. Such experiments do not model the process we want to investigate (transient debris jets above explosion sites), hence the need for a new type of setup.

Data acquisition. Our experiments, which are generally complete within less than one second after sending the trigger signal, are filmed with a high speed video camera (500 frames per second) and a digital video camera (25 frames per second) through the glass window at the front of the container. We simultaneously record up to five time-dependent physical parameters with a sampling rate of $5.7 \mathrm{kHz}$ (one measurement of each variable every $175 \mu \mathrm{s})$. The vertical force applied to the setup by the accelerating mass of particles is measured using a piezoelectric crystal force transducer, placed between a large mass (the solid steel cylinder) and the air injection + crucible system (Fig. 2). The driving pressure is measured using a pressure transducer, placed immediately beyond the solenoid valve. To achieve a constant driving pressure, compressed air is released into an expansion volume - thus the resulting driving pressure, as measured by the pressure transducer, is about half the initial air 
pressure (the volume of the steel pipe plus that of the crucible are equivalent to the volume of the rubber tube). Both transducers are connected to charge amplifiers. Airwaves above the setup are detected by a standard microphone placed in a rolled-up gas-permeable foam pad, which also prevents most particles from leaving the container. Seismic waves are measured using a broadband seismometer placed on the lab floor (vertical component, $\mathrm{kHz}$ range). Finally, short-time electrostatic perturbations are detected in a metal grid about $30 \mathrm{~cm}$ behind the setup; the grid is connected to a specially designed highresistance direct current amplifier (see Büttner et al. 1997, 2000, about this device and short-time electrical effects of volcanic eruptions).

Scaling. The issue of scaling is generally of prime importance when trying to apply the results of experimental simulations to natural phenomena. In this case, given that the natural process under study - upward propagation of a multiphase flow into a granular host - is poorly understood and not directly observable, comparisons between experiments and nature are not straightforward. In choosing the experimental parameters and materials we have taken into account the following considerations:

- The particles used in the experiments are much smaller than in nature, so that a comparable number of grains are mobilized in the flows. However, the particles are large enough to minimize electrostatic effects and cohesion.

- The values of the experimental parameters that most influence the flow velocities (initial gas pressures and host thicknesses) are chosen as to qualitatively reproduce the range of phenomena thought possible in debris-filled volcanic vents above explosion sites; we do not impose a control on flow velocities.

- The gas pressures were also chosen using insights gained from phreatomagmatic and "magma blowout" experiments at the same laboratory (e.g., Zimanowski et al. 1991, 1997). More specifically, during blowout experiments, magma was expelled from a crucible (of the same type as the one used here) using compressed air. The driving pressure was adjusted to match the exit velocities and the repulsion force recorded during phreatomagmatic interactions (again using the same crucible). Therefore this driving pressure represents the pressure of superheated steam formed after thermohydraulic explosions (Zimanowski 1998), and the gas pressures used for the current experiments are of the same order of magnitude. Laboratory molten fuel-coolant interactions are themselves energetically scaled relative to natural phreatomagmatic explosions, since they generate identical pyroclasts (Büttner et al. 2002).

\section{Experimental program}

During the first post-calibration phase runs (series A through F), we tested the effect of varying the particle size of the host and the initial air pressure in the reservoir using a constant depth $(14 \mathrm{~cm})$ of dry white beads as a host and the red glass beads as the injected material. We used three different host particle sizes, two initial air pressures, and we repeated each combination at least three times (Table 2). The effect of varying the grain size of the host while holding other parameters constant is noticeable but of a lesser magnitude than anticipated (details below). In the range of initial air pressures investigated, doubling the pressure while holding all other parameters constant induces large changes in system behaviour (described below).

We then doubled the injection depth (host thickness) to $28 \mathrm{~cm}$, to test the impact of this parameter (series G). We used only the 200-300 $\mu \mathrm{m}$ dry white beads for the host material, and varied the initial air pressure in the reservoir between 1 and $2 \mathrm{MPa}$. Dry red beads were injected. Again, we tested each configuration at least three times.

Finally, we tried a number of other configurations. We used moist white beads as a host (series $\mathrm{H}$ ); dry brown sand as a host and red beads as the injected material (series I and $\mathrm{J}$ ); and brown sand as a host, but injecting orange sand (series $\mathrm{K}$ ). For series $\mathrm{H}$ through $\mathrm{K}$, which were of a more exploratory nature, not all runs were multiply replicated.

\section{Results, series A to F}

Effects of varying initial air pressure. For a given injection depth (host thickness) and given materials, the behaviour of the system (e.g. erupting or non-erupting) is controlled by the initial gas pressure. Results from series A to F can be classified into three categories: (i) "erupting" runs during which some or all of the injected red beads become temporarily airborne (series A, C, E); (ii) "nonerupting" runs for which the initial gas pressure in the reservoir is enough to inject the red beads from the crucible into the host, but not enough for the resulting twophase flow (the 'bubble') to propagate to the surface of the host (series B, D, F); (iii) "failed" runs during which particles visible through the glass window move very little because the initial air pressure is too low relative to the mass of particles (see Table 2, note b).

"Non-erupting" runs are inferred to be equivalent to natural debris jets which remain confined inside a debris-filled volcanic vent (Fig. 3, Table 3), without producing subaerial eruptions (see White and McClintock 2001; Ross and White 2006). An expanding 'bubble' of air + red beads eventually collapses because the gas escapes through the permeable roof; meanwhile the red beads sediment into the transient cavity, which is also closing laterally because of inward-directed granular flow of the host at the base of the container. At the end of these runs, the layers of host material are not overturned as in cratering experiments using explosives (e.g., Johnson et al. 1969), or in some of our own experiments using higher pressures. The result is a steep to sub-vertical body of granular material having differing properties (here, colour) from those of the surrounding host; no "eruption" is necessary to produce such a body. 
Phenomena observed in "erupting' runs closely resemble those in "non-erupting" runs, except that the greater initial gas pressure allows the 'bubble' of air and red beads to breach the surface of the host. A typical 'erupting' run is described in Table 4 and illustrated in Figs. 4 and 5. Such runs also produce steep bodies similar to those observed within eroded diatremes, but when "eruption" occurs, the bodies of red beads are flared upwards, and accompanied by red-bead ejecta blanketing the surface.

Kinematic data. Using grabbed frames from the high-speed camera, we track the evolution of one angle and the position of three points through time (Fig. 6, lower right). Analysis shows that the propagation velocity of the air + red beads 'bubble' during its growth reaches about $5 \mathrm{~m} / \mathrm{s}$ for both series $\mathrm{A}$ and $\mathrm{C}$ runs. Maximum propagation velocities are measured 50 to $55 \mathrm{~ms}$ after opening of the valve (before that, red beads have not reached the glass window). Then the 'bubble's' propagation slows down until it stagnates (Fig. 6a). For the B and D series (nonerupting runs), maximum 'bubble' propagation velocities are about $2.5 \mathrm{~m} / \mathrm{s}$, due to the lower initial pressures (Fig. $6 c)$.

While the 'bubble' is growing, the host forms a 'dome' above it. We now describe what happens during "erupting" experiments (series A, C or E), taking run A6 as an example. The 'dome' quickly accelerates initially, then moves upward with a constant velocity of $2.3 \mathrm{~m} / \mathrm{s}$ (Fig. 6a) until it has propagated laterally to the sides of the model; this takes about $50 \mathrm{~ms}$ (Table 4, times 50 to 100). Meanwhile, the distance between the top of the 'bubble' and the top of the 'dome' is decreasing (the "arch" is thinning and white beads are moving outwards). The top of the 'dome' next slows down to $1.9 \mathrm{~m} / \mathrm{s}$ for about $50 \mathrm{~ms}$, while at the same time, movement of the top of the 'bubble' slows, which causes the "arch" to thicken (Fig. 6a). Thickening of the arch takes place because the host material forming the 'dome' is becoming inflated - less tightly packed - due to air escaping from the 'bubble' (evidence for this is seen as thin radial lines in the 'dome', interpreted as preferential air passages, for example on Fig. 4, frame 206). Eventually the arch expands to a discontinuous particle dispersion and it becomes impossible to determine a position for the top of the 'dome': the white beads hit the rolled foam pad, and fall back down (Fig. 4).

The maximum angle (from horizontal) reached by the 'dome' sides is almost $50^{\circ}$ in run A6 (Fig. 6b) and $45^{\circ}$ in run B2. This is almost double the angle of repose for this material so we are clearly not dealing with an equilibrium situation during 'dome' growth.

Time-dependent physical parameters. Of the five parameters measured, driving pressure and force records (e.g. Fig. 5) are the most relevant to this discussion. The rapidly rising driving pressure, in the initial stages of the experiments, is due to compressed air being released into the low pressure section beyond the valve and expanding to push the red glass beads upwards in the crucible. After the maximum is reached, the driving pressure declines rapidly. The fact that the pressure does not return to zero means that the gas in the steel pipe - where pressure is measured - is not in full equilibrium with the laboratory atmosphere after the pressure peak, possibly because some still slightly compressed air is trapped by fallen or left-over particles. This residual pressure does not tell us anything about the particle-gas system above.

The force curves represent the accelerated movement of the red glass beads in the crucible. The rising part of the force curves display the transition between the plug stage (cohesive coupling of the red beads) and the two phase stage by a distinctive kink in the slope. This kink coincides with the maximum driving pressure. As long as the crucible content is moving as a plug, the mechanical coupling of the adiabatic expansion of the driving gas to the particles is more or less linear, comparable to a solid bullet in a gun barrel. Once a two phase flow has been established, due to the compressible character, the expansion evolves into a semi-spherical geometry and the energy density (represented by the driving pressure) drops in an exponential way. The force signal, in many cases, displays a kink in the slope at that time.

The maximum acceleration, represented by the maximum force, is observed in the two-phase flow region of the particle/gas injection. In runs B2 (Table 2) and A6 (Table 3), the force peaks and the initiation of surface doming in the host are approximately coincident. This implies that the acceleration of the mobilized mass is greatest at this time. After the force peak, the particle/gas system decouples from the force recording system, i.e. the repulsion force drops to zero. Beyond this peak, the slope of the force curve corresponds to the relaxation characteristics of the measurement system. The apparent negative force is due to the lift-off of the crucible and its substructure (Fig. 2) and the following oscillations represent the frequency of its bouncing.

Impact of particle size. Changing the particle size of the host has a noticeable impact on the phenomena, but much less than that of gas pressure. Fig. 7 shows that for a constant initial pressure $(1.0$ or $0.5 \mathrm{MPa})$ and injection depth (host thickness), the timing and intensity of the measured peak driving pressure is similar regardless of the grain size of the host. Qualitative differences, however, are observed. For example, at the end of the A and E series runs, the crucible was filled with mixed red and white beads, whereas for the $\mathrm{C}$ series runs (finer particle size) it was entirely filled by white beads from the host. This is because a non-fluidized finer host seems to 'flow' inward better at the base of the container, relative to a coarser host, and is able to entirely replace the red beads in the crucible while the system is expanded. A wider range of grain sizes should be investigated to learn more about the effect of a changing particle diameter on the experimental flows. We suspect that in natural systems, the host particle mobility, or "flowability", effect would be most strongly associated with differences in host-debris sorting, particle interlocking and cohesion. 


\section{Results, G series}

In the $G$ series (Table 5), we investigate the effect of a different injection depth (host thickness). Using a doublethickness host $(28 \mathrm{~cm})$ means significantly increasing the initial gas pressure to obtain phenomena equivalent to those described above. For example, an initial air pressure of $2.0 \mathrm{MPa}$ is necessary to obtain an "eruption". A process not obvious with a thin host (series A to F) becomes apparent with a thicker host: the late decoupling of the gas phase into a rising air volume almost devoid of red glass beads. This is particularly clear at $1.5 \mathrm{MPa}$ in series $\mathrm{G}$ (Figs. 8 and 9, Table 6). This initial air pressure is not high enough to eject the red beads into the "atmosphere", so the result is partly comparable to the B series runs. However, during $\mathrm{B}$ series runs, the thin layer between the 'bubble' (red beads + gas) and the domed host allows excess air to escape, whereas with a host of double the thickness (series $\mathrm{G}$ ), the 'dome' angle is much gentler, and the layer between the 'bubble' and the top of host is much thicker (Fig. 8). Additionally, at $1.5 \mathrm{MPa}$, three times as much gas needs to escape relative to the amount in B series runs (0.5 MPa initial air pressure); these factors combine to produce a volume of air that segregates and rises after sedimentation of the red beads. In fact, a secondary air bubble is produced for all $28 \mathrm{~cm}$ experiments which do not "erupt" ( $\mathrm{G}$ and later series). Whether this process has natural analogues is uncertain, because water vapour is normally the most abundant gas in volcanic eruptions (e.g. Fisher and Schmincke 1984), and is condensible upon cooling.

\section{Results, other series}

The results of the remaining series will be described only in brief, as they were more exploratory in nature.

Moist host. Moistening a white-bead host (series $\mathrm{H})$ makes it cohesive, with the result that it fractures in a radial pattern during the doming phase (Fig. 10a). At the end of $\mathrm{H}$ series runs, a relatively steep crater is preserved (Fig. 10b), whereas for dry experiments the crater angle can be no more than the angle of repose of the material. These preliminary tests indicate that limited wetting of the granular host changes its behaviour significantly by increasing host cohesion and reducing its ability to deform by granular flow. Larger amounts of liquid water in the host would form a slurry; we have not investigated the effects of using such a host because doing so would require changes to the experimental setup, so that the slurry does not flow into the air pipe before the valve opens.

Sandy host. When injecting dry red beads into dry brown sand, a higher initial gas pressure is necessary to obtain results similar to the A (14 cm glass beads host) or $\mathrm{G}$ (28 cm host) series. For instance, for a $28 \mathrm{~cm}$-thick sandy host ( $\mathrm{J}$ series), we raise the initial pressure to $2.5 \mathrm{MPa}$ to produce a result approximately equivalent to that obtained at $2.0 \mathrm{MPa}$ with the same thickness of glass beads. This is not due to a difference in initial densities or porosities, because the hosts - sand and glass beads - are similar in those respects. The explanation for the greater pressure necessary for a similar result seems two-fold: sand does not flow as well as glass beads, as evidenced by a much higher angle of repose; also it might oppose more resistance to gas escape because of the slightly poorer sorting and more irregular grain shapes (so lower permeability and more interlocking of grains). The reduced permeability makes the sand enclose the 'bubble' more efficiently, while particle interlocking makes it more resistant to deformation.

Another difference in behaviour for a sandy host is that the red beads + gas 'bubbles' are more irregular in shape during their propagation. With glass beads as a host, the 'bubbles' are perfectly symmetrical and have very smooth shapes (e.g., Fig. 4, frame 96); not so with sand (e.g., Fig. 10c). This irregular shape of the expanding 'bubble' is likely caused by the heterogeneous nature of particle interlocking and permeability pathways in the sandy host. Finally, for the same host thickness and initial air pressure, red beads + gas 'bubbles' are narrower and less balloon-shaped using sand (e.g. run I3 vs. run B2; Fig. $10 \mathrm{e})$, reflecting the greater resistance to deformation. The overall difference between the behaviour of sand vs. glass beads could also be explained in part by a contrasting jammed state of the granular media, depending on the geometry of the force chain network and intensity of interparticle contacts within them (e.g., Cates et al. 1998).

Sand injected into sand. If the same brown sand as in series I and $\mathbf{J}$ is used as a host, but this time orange sand is injected (series K), the resulting 'bubble' is also irregular. Further, it develops a wide base (Fig. 10d), a phenomenon which is not seen when glass beads are injected.

\section{Discussion}

We discuss three main points: (1) the behaviour of the experimental flows, with special consideration of potential mixing between the host and the injected particles and the effect of the host type on the flows; (2) applicability of the experiments to maar-diatreme volcanoes; and (3) comparison with fluidized systems.

Behaviour of the experimental flows. The general aims of the experiments were to (a) study the upward propagation of gas-particle dispersions into a clastic host, and (b) learn about how injected particles could form cylindrical or conical bodies analogous to those inferred from fieldwork to exist in some volcanic vent fills. Ross and White (2006) deduced three end-member cases of debris-jet behaviour. It is interesting to compare these scenarios with our experiments. In Ross and White's case 1 , the jets propagated by "pushing the host material upwards and removing it from the site". On the highly simplified cartoons, the propagating jet was shown as flattopped and straight-walled. In the present experiments we show that a debris jet indeed propagates by pushing its clastic host upward; in the experiments, however - and very likely in nature as well - the propagating jet takes the form of a 'bubble'. Additionally, especially at the shallow depths investigated in these experiments, the host deforms by (i) upward doming because it is pushed by the expanding and buoyant 'bubble'; (ii) outward lateral flow 
of the domed material; (iii) expansion of the domed material because of upward momentum from the bubble and inter-particle air flow in the host; and (iv) inward granular flow at the base of the model, following the passage of the 'bubble'. The propagation of debris jets through granular hosts therefore seems much more complex than Ross and White (2006) envisaged, fully justifying the need for experimentation, even if imperfectly scaled.

Ross and White's end-member case 2 proposed that a "jet propagates upwards by entraining host debris, abrading particles from the conduit walls, and mixing everything together". Such processes are not observed experimentally: particularly when using glass beads, the 'bubble' walls are very smooth and the flow does not seem to entrain (stope) host material from the top. There is also little or no entrainment along the side walls of the 'bubble'. The implication is that during explosive subterranean eruptions, the mixing of recycled clasts and new juvenile particles must take place at or near the explosion sites, before focussed debris jets start to travel upwards. Once a debris jet is established through a nonfluidized granular host, there is no significant mixing between the jet and the host.

Limited mixing does take place in our experiments, but during the sedimentation stage rather than during bubble growth or breaching. When the injected particles fall and flow downward at the margins of the closing bubble (e.g., Fig. 8, frame 274), there is an opportunity for host incorporation. Mixing is more efficient for the more energetic "erupting" runs (compare Figs. 11b and 11a).

To illustrate the impact of the host properties on the final shape of the "intrusion" (the body of red beads), compare Fig. 11c and Fig. 11d. In both cases, the same thickness of host is used, with the same initial gas pressure. The sandy host, however, creates a very irregular 'bubble' of gas and red beads during injection; the 'bubble' rapidly collapses, causing sedimentation of most of the red beads; rising air "fingers" then temporarily entrain some red beads, which are left behind and contribute to the complicated shape of the final deposit. So all else being equal, sand resists better the propagation of the injected gas-particle flow because of the wider grainsize range (which reduces permeability) and better grain interlocking (which increases strength); it also creates more irregular 'bubbles' and final deposits.

Applicability to maar-diatreme volcanoes. To more specifically relate experimental processes and products to those of discrete explosions during volcanic eruptions, consider an explosion in a vent structure filled with volcaniclastic material - such as an existing diatreme. Such explosions have been specifically inferred to take place in diatremes as a result of magma-water interaction (e.g., Lorenz 1986), but for the current discussion any mechanism capable of producing discrete explosions of similar timescale is acceptable. The explosion will fragment some of the magma, and entrain resultant new juvenile particles, plus some pre-existing vent-filling debris, into an expanding 'bubble', which is highly buoyant relative to enclosing material because the moving mixture contains a large proportion of low-density fluids. Particles will be propelled to the bubble's walls as the 'bubble' expands and elongates vertically. At this stage, a subterranean debris jet can be said to exist, and if the explosion site is not too deep, the surface of the vent-fill might be pushed upwards and outwards to make space for the expanding fluids, as illustrated by our experiments and by full-scale artificial blasts (Fig. 12).

In nature the overburden pressures (due to the weight of overlying particles) at the bottom of diatremes 100 s to 1000 s of metres deep will be much larger than overburden pressures at the base of the model in our experiments. As a natural debris jet rises, the enclosing material will exert diminishing confining pressures, allowing the gases to expand. This does not guarantee that the jet will rise all the way to the surface because other controls, such as gravity and condensation of water vapour with adiabatic cooling, are working against it.

In the case of a non-erupting debris jet, during the collapse of the 'bubble', the host will flow inwards to occupy newly available space, whereas the debris formerly suspended in the low-density fluids will sediment rapidly downwards. The final deposit will be a subvertical, nonbedded, cylindrical body of volcaniclastic material enriched in juvenile clasts compared to the adjacent host (because magma has been fragmented and the new juvenile fragments entrained by the expanding fluids). For debris jets that reach the ground surface, the within-vent deposits may be more conical (flaring upward) in shape.

In the experiments we do not model the initial phase during which new juvenile clasts are mixed with existing vent-filling debris, just after the explosion; instead, we start with the next step, when a mixture of clasts and fluids propagates upward into granular material. The red beads in the experiments thus represent the mixture of new juvenile clasts and pre-existing debris, whereas the white beads represent the pre-existing vent fill. For comparison, Fig. 13 shows a steep contact between lapilli-tuff inferred to have been injected into a countryrock rich tuff-breccia interpreted to represent the preexisting vent fill at Standing Rocks diatreme, Hopi Buttes, Arizona.

If a volcanic explosion occurs in country rock immediately underlying a debris-filled structure, as in the root zone of a diatreme, then the deposit will differ. The fragments produced upon explosion will be a mixture of juvenile fragments and abundant enclosing country rock; expansion followed by 'bubble' collapse will be similar to that described above, but the final deposit might be richer in country rock material than the host. Such country rockrich pipes were mapped in the Coombs Hills vent complex, Antarctica (McClintock and White 2006; Ross and White 2006). In the experiments conical or cylindrical zones are formed in both "erupting" and "non-erupting" runs.

Comparison with fluidized systems. Our experiments are not, as mentioned previously, designed to address the same phenomena as do fluidization 
experiments, but both have been proposed to represent aspects of diatreme-forming eruptions. Here we briefly compare key aspects of the two different types of experiments.

Scaling - Our experiments simulate explosions that inject beads and gas from the source area into overlying debris. The "debris jets" are dynamically scaled to explosive phreatomagmatic interactions in terms of energy release; we are not, however, examining fragmentation. The success of our experiments in producing deposits analogous to natural ones suggests that the experiments have succeeded in exploiting what Paola (2006) has termed "natural similarity" occurring across scales. The fact that fluidization experiments, similarly incapable of full dynamic scaling and lacking any injected "juvenile analogue" particles, are also able to reproduce some aspects of natural deposits indicates that they too satisfactorily mimic some elements of volcanic systems.

Duration - A fundamental difference between these experiments and fluidization experiments is their duration. Our experiments address individual explosions; they are not intended to be representative of entire volcano-forming events, or even entire eruptions. Fluidization experiments last orders of magnitude longer than our injections (seconds to minutes vs. $<1 \mathrm{~s}$ ), but are shorter by similar orders of magnitude than observed maarforming eruptions inferred to have produced diatremes (Müller and Veyl 1957; Woolsey et al. 1975; Self et al. 1980; Walters et al. 2006).

Deposits - It is not possible to compare deposits from our experiments with those of fluidization experiments because the latter involve only gas and host materials. For natural deposits in vents, we have argued that explosion sites are not fixed (White and McClintock 2001; McClintock and White 2006; Ross and White 2006), thereby explaining complex cross-cutting deposit bodies as well as transport of wall-derived particles.

\section{Conclusions}

The term "debris jets" is used to describe an upwardflowing stream of particles and low-density fluids formed above subterranean explosion sites such as those in volcanic vents or above artificial blasts. Our laboratory experiments on a simplified system (air and coloured glass beads injected into white glass beads or sand) produce bodies of granular material having differing properties from the host. Such bodies are also observed in eroded volcanic vents such as diatremes or phreatomagmatic vent complexes.

In our experiments, the injected air and coloured beads form a bubble-shaped two-phase flow which propagates mainly by pushing the host upwards and outwards, eventually producing a relatively steep 'dome'. For runs using shallow injection depths (thin host), but in which the initial air pressure in the reservoir is relatively low, the injected material does not propagate to the surface; after reaching a maximum expansion, the 'bubble' collapses because the gas phase escapes through the permeable roof. Meanwhile the coloured glass beads, formerly transported in the gas phase, sediment in the closing transient cavity, forming a narrow cylindrical pipe.

For runs using a shallow injection depth but a higher initial gas pressure, the expanding 'dome' is broken by the propagating two-phase injection and "eruption" occurs. The deposit of coloured beads therefore assumes a flaring upward or conical shape. If repeated several times such injections - whether erupting or wholly subterranean -, accompanied by collapse-capture of a central zone of initially upward-driven material, provide a compelling explanation for the origin and characteristics of multiple cross-cutting bodies that typify diatreme deposits.

Changing the size of the host glass beads, while holding all other parameters constant, does not have an important effect on the experiments under the particle size range investigated. The injection depth and the initial gas pressure are the important flow-controlling parameters: doubling the injection depth (host thickness) requires an approximate doubling of the initial air pressure to produce similar phenomena. At these greater injection depths, the doming effect is much less pronounced for non-erupting runs, but a separate "air-pocket" tends to rise and pierce the host surface, to carry the excess gas away. Using sand as the host material, instead of glass beads, also requires increasing the initial gas pressure to obtain similar phenomena. A sandy host also produces more irregularly shaped injections, which are probably better analogs to natural debris jets.

\section{Acknowledgements}

We thank the University of Otago for a bridging grant to Ross and research funds to White, who also acknowledges a subcontract from the Institute of Geological and Nuclear Sciences (New Zealand). The manuscript was written in part during Ross' postdoctoral fellowship at the Geological Survey of Canada (funding: NSERC Visiting Fellowship in Canadian Government Laboratories, with support from the Chief Scientist Office, Earth Sciences Sector, Natural Resources Canada). We thank V. Lorenz, B.F. Houghton, M.T. Gudmundsson and M. McClintock for discussions about diatremes and phreatomagmatism. Reviewers O. Roche and P. Petrosino, as well as Associate Editor J. Phillips, provided useful comments on the submitted manuscript.

\section{References}

Büttner R, Zimanowski B (1998) Physics of thermohydraulic explosions. Phys Rev E 57:5726-5729

Büttner R, Röder H, Zimanowski B (1997) Electrical effects generated by experimental volcanic explosions. Applied Physics Letters 70:1903-1905

Büttner R, Zimanowski B, Röder H (2000) Short-time electrical effects during volcanic eruption: experiments and field measurements. J Geophys Res 105:2819-2828

Büttner R, Dellino P, La Volpe L, Lorenz V, Zimanowski B (2002) Thermohydraulic explosions in phreatomagmatic eruptions as evidenced by the comparison between pyroclasts and products from Molten Fuel Coolant Interaction experiments. J Geophys Res 107:Art. 2277 
Carlson RH, Jones GD (1965) Distribution of ejecta from cratering explosions in soils. J Geophys Res 70:1897-1910

Cates ME, Wittmer JP, Bouchaud J-P, Claudin P (1998) Jamming, force chains, and fragile matter. Physical Review Letters 81(9). DOI: 10.1103/PhysRevLett.81.1841

DOE (1962) Project Sedan - Part 3 [historical test film 0800030]. U.S. Department of Energy (http://www.nv.doe.gov/library/films/film.aspx?ID=88)

DOE (2000) United States Nuclear Tests, July 1945 through September 1992. Report DOE/NV--209-REV 15, U.S. Department of Energy, Nevada Operations Office, pp 1-162 (http://www.nv.doe.gov/library/publications/historical/DOE NV_209_REV15.pdf)

Fisher RV, Schmincke H-U (1984) Pyroclastic Rocks. SpringerVerlag, Berlin, pp 1-472

Goto A, Taniguchi H, Yoshida M, Ohba T, Oshima H (2001) Effects of explosion energy and depth to the formation of blast wave and crater: Field explosion experiment for the understanding of volcanic explosion. Geophysical Research Letters 28:4287-4290

Hearn BC (1968) Diatremes with kimberlitic affinities in northcentral Montana. Science 159:622-625

Johnson SW, Smith JA, Franklin LK, Moraski LK, Teal DJ (1969) Gravity and atmospheric pressure effects on crater formation in sand. J Geophys Res 74:4838-4850

Kokelaar BP (1983) The mechanism of Surtseyan volcanism. J Geol Soc [London] 140:939-944

Lorenz V (1986) On the growth of maars and diatremes and its relevance to the formation of tuff rings. Bull Volcanol 48:265-274

McClintock MK, White JDL (2006) Large-volume phreatomagmatic vent complex at Coombs Hills, Antarctica records wet, explosive initiation of flood basalt volcanism in the Ferrar LIP. Bull Volcanol 68:215-239

Müller G, Veyl G (1957) The birth of Nilahue, a new maar type volcano at Rininahue, Chile. $20^{\text {th }}$ International Geological Congress, Mexico, pp 375-396

Nichols RJ, Sparks RSJ, Wilson CJN (1994) Experimental studies of the fluidization of layered sediments and the formation of fluid escape structures. Sedimentology 41:233-253

Ohba T, Taniguchi H, Oshima H, Yoshida M, Goto A (2002) Effect of explosion energy and depth on the nature of explosion cloud: A field experimental study. J Volcanol Geotherm Res 115:33-42

Paola C (2006) Natural and imposed similarity in experimental stratigraphy [abstract]. $17^{\text {th }}$ International Sedimentological Congress, Fukuoka, Japan, Volume A, pp 96

Ross P-S, White JDL (2006) Debris jets in continental phreatomagmatic volcanoes: a field study of their subterranean deposits in the Coombs Hills vent complex, Antarctica. J Volcanol Geotherm Res 149:62-84 [doi:10.1016/j.jvolgeores.2005.06.007]

Self S, Kienle J, Huot J-P (1980) Ukinrek Maars, Alaska II. Deposits and formation of the 1977 craters. J Volcanol Geotherm Res 7:39-65

Walters AL, Phillips JC, Brown RJ, Field M, Gernon T, Stripp G, Sparks RSJ (2006) The role of fluidisation in the formation of volcaniclastic kimberlite: grain size observations and experimental investigation. J Volcanol Geotherm Res 155:119-137

White JDL (1991) Maar-diatreme phreatomagmatism at Hopi Buttes, Navajo Nation (Arizona), USA. Bull Volcanol 53:239-258

White JDL, McClintock MK (2001) Immense vent complex marks flood-basalt eruption in a wet, failed rift: Coombs Hills, Antarctica. Geology [Boulder] 29:935-938

Wilson CJN (1980) The role of fluidization in the emplacement of pyroclastic flows: an experimental approach. J Volcanol Geotherm Res 8:231-249

Wohletz KH (1986) Explosive magma-water interactions: Thermodynamics, explosion mechanisms, and field studies. Bull Volcanol 48:245-264

Woolsey TS, McCallum ME, Schumm SA (1975) Modeling of diatreme emplacement by fluidization. Physics and Chemistry of the Earth 9:11-24

Zimanowski, B (1998) Phreatomagmatic explosions. In: Freundt, A and Rosi, M (eds), From magma to tephra. Developments in volcanology 4, Elsevier, Amsterdam, pp 25-54

Zimanowski B, Fröhlich G, Lorenz V (1991) Quantitative experiments on phreatomagmatic explosions. J Volcanol Geotherm Res 48:341-358

Zimanowski B, Büttner R, Lorenz V, Häfele H-G (1997) Fragmentation of basaltic melt in the course of explosive volcanism. J Geophys Res 102:803-814

Table 1 Measured properties of the sands used in the experiments

\begin{tabular}{lccccccc}
\hline Type of sand & $\begin{array}{c}\text { Dry density } \\
\left(\mathrm{g} / \mathrm{cm}^{3}\right)\end{array}$ & $\begin{array}{c}\text { Porosity } \\
(\%)\end{array}$ & Angle of repose & $\phi_{16}{ }^{\mathrm{a}}$ & $\phi_{50}$ & $\phi_{84}$ & Inman sorting $^{\mathrm{b}}$ \\
\hline Brown & 1.52 & 35 & $33^{\circ}$ & 0.60 & 1.30 & 1.85 & Moder. well sorted \\
Orange & 1.54 & 42 & $35^{\circ}$ & 1.25 & 1.62 & 2.15 & Well sorted \\
White & 1.43 & 37 & n.d. & 1.22 & 1.60 & 2.00 & Well sorted \\
\hline
\end{tabular}

a. Phi size calculated as $\phi=-\log _{2}(d)$ where $d$ is the diameter of the particles in $\mathrm{mm}$. $\phi_{16}$ is the grain size above which $16 \%$ of the cumulative weight of a sample would be retained in a sieve, and so forth for $\phi_{50}$ (median size) and $\phi_{84}$. These values are read on a plot of the cumulative weight in percent versus the grain size in phi units.

b. Inman sorting calculated as $1 / 2\left(\phi_{84}-\phi_{16}\right)$. 
Table 2 Experimental parameters for series A to $\mathrm{F}^{\mathrm{a}}$

\begin{tabular}{|c|c|c|c|}
\hline Series & $\begin{array}{l}\text { Particle diameter of host } \\
\qquad(\mu \mathrm{m})\end{array}$ & $\begin{array}{l}\text { Initial air pressure in reservoir } \\
\qquad(\mathrm{MPa})\end{array}$ & Number of successful repetitions ${ }^{b}$ \\
\hline A & $200-300$ & 1 & 6 \\
\hline B & $200-300$ & 0.5 & 3 \\
\hline $\mathrm{C}$ & $100-200$ & 1 & 3 \\
\hline $\mathrm{D}$ & $100-200$ & 0.5 & 3 \\
\hline $\mathrm{E}$ & $300-400$ & 1 & 3 \\
\hline $\mathrm{F}$ & $300-400$ & 0.5 & 3 \\
\hline
\end{tabular}

a. Constant parameters in these runs: initial height of dry white beads $14 \mathrm{~cm}$, injected material consists of dry red beads.

b. Unsuccessful runs occurred mainly during series B and F, when the system "jammed", i.e. the red beads did not invade the host after the valve opened to release the compressed air. This might have been due to glass beads falling into the air conduits and jamming them, and/or to an initial air pressure $(0.5 \mathrm{MPa})$ not sufficient to move the red beads upward in the crucible and into the white beads.

Table 3 Key events during experimental run B2 (see Table 2 for experimental parameters and Fig. 3 for illustrations)

\begin{tabular}{|c|c|}
\hline $\begin{array}{l}\text { Time } \\
(\mathrm{ms}) *\end{array}$ & Event \\
\hline 000 & Trigger signal sent to solenoid, which opens within a few ms and liberates pressurized air \\
\hline 030 & Peak driving pressure $(0.23 \mathrm{MPa})$ recorded \\
\hline 032 & $\begin{array}{l}\text { The two horizontal markers in white beads start to move slightly upwards; no discernable movement } \\
\text { of surface of host at this stage }\end{array}$ \\
\hline 050 & Initiation of surface doming in host \\
\hline 056 & Peak force $(130 \mathrm{~N})$ recorded \\
\hline 058 & $\begin{array}{l}\text { Red beads become visible through the glass window as a } 2 \mathrm{~cm} \text {-wide circular zone; zone of red beads } \\
\& \text { eventually red beads + gas, will grow as a circle until } \sim 088 \mathrm{~ms}\end{array}$ \\
\hline 088 & $\begin{array}{l}\text { 'Bubble' now dominated by dilute suspension of red beads into gas; this will expand as an ellipse (in } \\
\text { the window section) until } 120 \mathrm{~ms}\end{array}$ \\
\hline 120 & $\begin{array}{l}\text { Base of elliptical 'bubble' starts to pinch because of inward movement of granular host (white beads); } \\
\text { from then on, top of 'bubble' still rises but 'bubble' does not grow laterally (see Fig. 3a) }\end{array}$ \\
\hline 178 & Base of the 'bubble' now fully closed; rapid sedimentation of red beads becomes clearly visible \\
\hline 204 & $\begin{array}{l}\text { Maximum height of 'bubble' reached; 'bubble' top starts to collapse downwards while sedimentation } \\
\text { of red beads continues (Fig. 3b) }\end{array}$ \\
\hline 338 & $\begin{array}{l}\text { 'Bubble' has disappeared completely; a columnar body of read beads has been formed - this body has } \\
\text { a surface area (in the window section) four times smaller than the area occupied by the 'bubble' at } \\
196 \mathrm{~ms} \text { (near its maximum extent) }\end{array}$ \\
\hline
\end{tabular}

* All times referring to visual observations are even numbers because the high-speed camera records at 500 frames per second. 
Table 4 Key events during experimental run A6 (see Table 2 for experimental parameters and Fig. 4 for illustrations)

\begin{tabular}{|c|c|}
\hline $\begin{array}{l}\text { Time } \\
(\mathrm{ms}) *\end{array}$ & Event \\
\hline 000 & Trigger signal sent to solenoid, which opens within a few ms and liberates pressurized air \\
\hline 031 & Peak driving pressure (0.48 MPa) recorded (Fig. 5) \\
\hline 040 & $\begin{array}{l}\text { The two horizontal markers in white beads and the surface of the host start to move slightly upwards } \\
\text { (read beads are moving in the crucible; this pushes the host upwards) }\end{array}$ \\
\hline 047 & Peak force $(354 \mathrm{~N})$ recorded (Fig. 5) \\
\hline 050 & $\begin{array}{l}\text { Top of the 'dome' (expanding host) has now accelerated to a constant vertical velocity of about } \\
2.3 \mathrm{~m} / \mathrm{s} \text { and will keep this velocity until about } 100 \mathrm{~ms} \text { (Fig. 6a, see "top dome A6"); meanwhile, } \\
\text { 'dome' sides are getting steeper (Fig. 6b) and the 'dome' is propagating laterally outwards. The left } \\
\text { extremity of the top surface (taken as typical for both extremities) is moving upward at only } 0.7 \mathrm{~m} / \mathrm{s} \\
\text { and will keep this constant velocity until about } 100 \mathrm{~ms} \text { (Fig. 6b) }\end{array}$ \\
\hline 054 & $\begin{array}{l}\text { Red beads, probably without too much air at this stage, become visible through the glass window as a } \\
\text { circular zone; zone of red beads \& eventually red beads }+ \text { gas, will grow as a circle until } \sim 066 \mathrm{~ms}\end{array}$ \\
\hline 066 & $\begin{array}{l}\text { 'Bubble' now grows as an ellipse (with a truncated base) against the glass window. Particle density in } \\
\text { bubble is decreasing as the amount of air increases }\end{array}$ \\
\hline 096 & $\begin{array}{l}\text { Base of elliptical 'bubble' starts to pinch because of inward movement of granular host (white beads), } \\
\text { but bubble width is still increasing higher up. Particle density in the middle of the 'bubble' is small } \\
\text { enough to see the white host at the back of the model through the 'bubble'. The slightly darker } \\
\text { pinkish layer at the top of the 'dome' has thickened from } 1.1 \mathrm{~cm} \text { initially to } 2.5 \mathrm{~cm} \text { at this stage (this } \\
\text { layer is accelerating faster than the rest of the host) }\end{array}$ \\
\hline 100 & $\begin{array}{l}\text { The steep part of the 'dome' has propagated to the sidewalls of the model and the upward velocity of } \\
\text { the top of the 'dome' decreases to about } 1.9 \mathrm{~m} / \mathrm{s} \text { (Fig. } 6 \mathrm{a} \text { ) }\end{array}$ \\
\hline 110 & Maximum 'dome' angle is reached (about $50^{\circ}$ from horizontal, Fig. 6b) \\
\hline 120 & $\begin{array}{l}\text { The left extremity of the top surface of the host accelerates to a new upward velocity of } 2.4 \mathrm{~m} / \mathrm{s} \text { (Fig. } \\
6 \mathrm{~b} \text { ). At this stage the distribution of red beads in the 'bubble' appears approximately annular (much } \\
\text { higher near the sides, with nearly pure gas in the centre, the density limit being relatively sharp) }\end{array}$ \\
\hline 136 & $\begin{array}{l}\text { Inside the expanded host, radial darker lines are becoming faintly visible. These are interpreted as } \\
\text { preferential gas escape pathways. These lines remain visible until about } 246 \mathrm{~ms}\end{array}$ \\
\hline 156 & $\begin{array}{l}\text { The base of the 'bubble' is now fully closed due to inward movement of granular host; the two sides } \\
\text { of the host 'collide' in the centre and a dense, secondary upward flow dominated by white beads (at } \\
\text { least near the window) starts to form. The top part of the host is now considerably expanded (low } \\
\text { particle density) and hits the rolled foam pad. The gas zone inside the 'bubble' is now funnel-shaped }\end{array}$ \\
\hline 172 & $\begin{array}{l}\text { 'Bubble' reaches maximum width, occupying slightly over a third of the host width. The secondary } \\
\text { flow of white beads has moved } 6.5 \mathrm{~cm} \text { upwards in } 18 \mathrm{~ms}(\mathrm{v}=3.6 \mathrm{~m} / \mathrm{s})\end{array}$ \\
\hline 200 & $\begin{array}{l}\text { Upward velocity of top of 'bubble' reaches zero (Fig. 6a) and will become negative but very low for } \\
\text { the next } 100 \mathrm{~ms} \text {. The secondary flow of white beads is 'fountaining' inside the 'bubble' (see Fig. 4). } \\
\text { Apart from this 'fountain', the system will now almost stagnate for over } 70 \mathrm{~ms}\end{array}$ \\
\hline 272 & $\begin{array}{l}\text { Downward movement of the expanded material previously involved in the 'dome' is becoming } \\
\text { apparent }\end{array}$ \\
\hline 290 & $\begin{array}{l}\text { The 'fountain' has reached the top of the 'bubble', which is becoming blurred; from this point the } \\
\text { expanded material accelerates back down }\end{array}$ \\
\hline
\end{tabular}

* All times referring to visual observations are even numbers because the high-speed camera records at 500 frames per second. 
Table 5 Experimental parameters for series $\mathrm{G}$ to $\mathrm{K}$

\begin{tabular}{ccccc}
\hline Series & Host type & $\begin{array}{c}\text { Host height } \\
(\mathrm{cm})\end{array}$ & Injected material & $\begin{array}{c}\text { Initial air pressure in reservoir } \\
(\mathrm{MPa})\end{array}$ \\
\hline $\mathrm{G}$ & $\begin{array}{c}\text { Dry white glass beads } \\
200-300 \mu \mathrm{m}\end{array}$ & 28 & Dry red beads & 1.0 to 2.0 \\
$\mathrm{H}$ & $\begin{array}{c}\text { Moist white glass } \\
\text { beads 200-300 } \mu \mathrm{m}\end{array}$ & 28 & Dry red beads & 1.0 \\
$\mathrm{I}$ & Dry brown sand & 14 & Dry red beads & 0.5 to 1.0 \\
$\mathrm{~J}$ & Dry brown sand & 28 & Dry red beads & 1.5 to 2.5 \\
$\mathrm{~K}$ & Dry brown sand & 28 & Dry orange sand & 2.0 \\
\hline
\end{tabular}

Table 6 Key events during experimental run G11 (see Fig. 8 for illustrations)*

\begin{tabular}{lc}
\hline $\begin{array}{l}\text { Time } \\
(\mathrm{ms})\end{array}$ & Event \\
\hline
\end{tabular}

000 Trigger signal sent to solenoid, which opens within a few $\mathrm{ms}$ and liberates pressurized air

035 Peak driving pressure (0.75 MPa) recorded (Fig. 9)

042 The lower two horizontal markers in white beads start to move slightly upwards, but the surface of the host is stable

$050 \quad$ Peak force $(596 \mathrm{~N})$ recorded (Fig. 9)

056 Red beads become visible through the glass window

082 The 'bubble' of air + red beads appears circular. Until 138, this ' bubble' grows as an ellipse (with a truncated base)

138 Base of 'bubble' starts to pinch because of inward movement of granular host; also, top of 'bubble' flattens (while still moving upward until 198) because a half-sphere-shaped zone immediately above the 'bubble' is starting to collapse

198 The top of the 'bubble' of air + red beads has reached its maximum elevation; almost all the red beads are near the margins of the 'bubble' and they start sedimenting downward and inward

250 The top surface of the host (the 'dome') reaches its maximum elevation and starts moving back downwards

258 The base of the air + red beads 'bubble' is fully pinched. Until about 334, a column of red beads forms while the air + red beads 'bubble' is disappearing (the air is moving up and the beads are moving down). Meanwhile, the space immediately above the disappearing red 'bubble' is being occupied by a progressively larger volume of air with a low concentration of white beads (derived from the collapsed half-sphere zone mentioned at 138)

334 A suspension of red beads into air is no longer visible, but air still rises while more and more of the host is mobilized into the roof collapse

382 A bulge appears at the top of the 'dome' because of a volume of air, devoid of red beads, is reaching the surface of the host

402 A distinct air-filled cavity is no longer apparent through the glass window

414 The air pocket mentioned at 382 is piercing the host's surface

* Experimental parameters: $28 \mathrm{~cm}$ of 200-300 $\mu \mathrm{m}$, dry, non-fluidized white (pinkish) glass beads as host; dry red beads of the same size as injected particles; initial gas pressure in reservoir 1.5 MPa. All times referring to visual observations are even numbers because the high-speed camera records at 500 frames per second. 


\section{Figures}

1. Field photograph (a) and line drawing (b) from the erosional remnant of the lower unbedded part of a diatreme structure at Standing Rock in the Hopi Buttes Volcanic Field on the Colorado Plateau, USA (White 1991) (near-vertical rock cliff). The bold dashed subvertical lines represent contacts between cross-cutting volcaniclastic zones - numbered from one to seven without chronological implications - having different clast populations and matrix colour. Paler lines show joints in the rock, with the intensity of jointing also differing from zone to zone.

2. Schematic drawing of the experimental setup. At the beginning of each run, the steel crucible is filled with the material to be injected, whereas the overlying space between the wooden planks and the glass window is filled with the host material, up to the marked dashed line (for the $14 \mathrm{~cm}$ configuration; twice as high for the $28 \mathrm{~cm}$ configuration). Compressed air is transferred from the air cylinder into the rubber tube but held up by the computer-controlled valve. When the valve opens, compressed air is released into the steel pipe and then pushes the material from the steel crucible into the 'host' above. All objects on the illustration were drawn exactly to scale except the air cylinder, the seismometer and the charge amplifiers.

3. Typical run from series B during which injected red beads and compressed air propagate into host, but do not reach the surface. Grabbed video frames of run B2 show (a) growth of the 'bubble' of air + red glass beads inside the granular host (white glass beads), and (b) collapse of the 'bubble' with sedimentation of red beads. The scale bar is graduated in $\mathrm{cm}$. Superimposed dashed lines show the position of the 'bubble' at current and earlier times, expressed in milliseconds $(0 \mathrm{~ms}=$ trigger signal sent to valve). The lower parts of curves in (b) show the sedimentation front rising with time. At $338 \mathrm{~ms}$, the 'bubble' has fully collapsed. Experimental conditions: see Table 2. The run is described step by step in Table 3.

4. Typical run from series A during which most of the injected particles (red glass beads) become temporarily airborne. The sequence of grabbed video frames (run A6) shows the time in $\mathrm{ms}$ in the upper right corner of each image ( $0 \mathrm{~ms}=$ trigger signal sent to valve). The scale bars are graduated in $\mathrm{cm}$. In this particular run, a slightly darker layer about $1.1 \mathrm{~cm}$ thick was used at the top of the host (total height $14 \mathrm{~cm}$ ). Note how at the end of the sequence this darker pink material has moved toward the sides. The run is described step by step in Table 4 and the driving pressure and force records are shown in Fig. 5.

5. Driving pressure and force record for runs A6 (illustrated in Fig. 4) and A1 (shown for comparison). The driving pressure starts to increase a few ms after the trigger signal is sent to the solenoid valve (at $\mathrm{t}_{0}=0$ ) and peaks at $\mathrm{t}=31 \mathrm{~ms}$ (for A6), rapidly declining afterwards. The force becomes positive slightly later than the driving pressure does, becomes the glass beads need to start moving for unloading of the force transducer to occur. The force peaks at $t=47 \mathrm{~ms}$ (run A6) during the rapid pressure decline; the force peak corresponds to the maximum upward acceleration of the glass beads. Run A1 displays a secondary force peak before the main peak; this feature is typical of most experiments for series A to G. The twitch in the A6 curves at about $260 \mathrm{~ms}$ is not meaningful.

6. Graphs showing the changing point positions and angles versus time for experimental series A and B, measured on highspeed camera records. (a) Vertical position of the top of the 'bubble' (injected red beads + gas) and the top of the 'dome' (deformed host, middle point) during three A series runs. (b) Vertical position of the left extremity of the surface of the host, and maximum 'dome' angle, for run A6 only. (c) Vertical position of the top of the 'bubble' and the top of the 'dome' during three B series runs. In all plots, positions are missing above about $175 \mathrm{~mm}$ (exact level varies for each run) because of poor lighting above this height, except for run A6 during which special lighting was used. Also the 'top dome B3' data is discontinuous on the right side of the plot because of bad image quality on the video record.

7. Comparison of the timing and intensity of the peak driving pressure for different runs at 1.0 MPa initial air pressure (filled symbols) and 0.5 MPa initial air pressure (open symbols). All other parameters are held constant except the grain size of the host, varying from 100-200 $\mu \mathrm{m}$ (series C and D) to 300-400 $\mu \mathrm{m}$ (series E and F). See Table 2 for complete experimental parameters. Note that the intensity of the peak driving pressure for each run depends on the initial pressure in the reservoir, which cannot be exactly controlled. The peak driving pressures measured are approximately half of the initial reservoir pressures (see text for explanation).

8. A series $\mathrm{G}$ run at $1.5 \mathrm{MPa}$ initial gas pressure, during which a gas volume rises to the surface of the host without transporting injected red beads. The sequence of grabbed video frames (run G11) shows the time in ms in the upper left corner of each frame $(0 \mathrm{~ms}=$ trigger signal sent to valve). The scale bars are graduated in $\mathrm{cm}$. Here $14 \mathrm{~cm}$ of pink beads (white beads contaminated by red beads in previous runs), overlain by $14 \mathrm{~cm}$ of paler pink beads was used. Note how the 'dome' is much gentler in angle than in series A (which used a 50\% thinner host). A significant portion of the top host layer (paler pink) is transferred to the sides of the model during doming. The run is described step by step in Table 6 and the driving pressure and force records are shown in Fig. 9. 
9. Driving pressure and force record for run G11 (illustrated in Fig. 8). The curves are similar in shape to those shown for run A1 (Fig. 5), except that the minor peak in the force curve (which occurs at the same time that peak pressure is reached, $\mathrm{t}=35 \mathrm{~ms})$ is more clearly defined. The main force peak $(\mathrm{t}=50 \mathrm{~ms})$ happens during the decline in driving pressure.

10. Selected grabbed frames for experiments made with non-standard conditions (see Table 5 for parameters). Using moist glass beads as a host renders it cohesive so that (a) fractures form during the doming phase and (b) the final crater is much steeper than with a dry host (run H2, 1.0 MPa initial air pressure). (c) Injecting air and dry red glass beads into a dry sandy host produces a more irregular 'bubble' during run J4 (2.5 MPa initial air pressure). (d) Injecting air + dry orange sand into a dry sandy host produces a 'bubble' with a wider base during run K1 (2.0 MPa initial air pressure). (e) Comparison of run I3 (photo and white lines; sandy host) and run B2 (overlaid yellow dashed lines; glass beads as a host), just before the base of the bubble pinches. The sandy host generates a narrower 'bubble' for the same initial conditions (14 cm host, $0.5 \mathrm{MPa})$. The bottom parts of the frames in (c) and (d) are lit more strongly than the upper parts, and the 'bubbles' of particles and gas are partly hidden by dust clouds in front of the model.

11. Photographs of the final results for (a) a "non-erupting" B series run; (b) an "erupting" A series run; (c) a "nonerupting" G series run; and (d) a "non-erupting" J series run. Scale bars are graduated in centimetres. Comparison of (a) and (b), which are for experiments using the same host thickness and properties (white glass beads of the same size), indicates that higher pressure runs create a flaring-upward body of red beads, whereas the body is more cylindrical for non-erupting runs. A cylindrical red body is also seen in (c), using a double thickness of host. In this run, "pinkish" beads were used as a host (white beads contaminated during previous runs). The apparent "crater" shape of the final surface in (a)-(c) and the "devil's horns" in (a) and (c), are caused by final subsidence of the granular material into the crucible. Note the overturned upper blue marker in (b), whereas in the non-erupting runs the markers are not overturned. Although the run illustrated in (d) has the same host thickness and the same initial gas pressure than that shown in (c), the use of a sandy host changes the shape of the red body considerably.

12. Artificial underground explosions, like our analogue experiments, produce transient surface doming if their scaled depths are not too great. The sequence of grabbed frames from an archive film (DOE 1962) shows this doming phenomenon for the July 1962 "Sedan" shot, a 104 kiloton nuclear detonation. The device was buried under $194 \mathrm{~m}$ of desert alluvium (DOE 2000) and eventually produced a crater $98 \mathrm{~m}$ deep and $390 \mathrm{~m}$ in diameter. The last frame represents the maximum development of the dome ( $88 \mathrm{~m}$ higher than the original ground surface), just before "venting" started at $\mathrm{t}=3 \mathrm{~s}$.

13. Field photograph (visible cliff height $\sim 10 \mathrm{~m}$ ) showing more juvenile-rich tuff-breccia body (left) steeply cross-cutting a volcaniclastic breccia rich in country-rock fragments. Hopi Buttes, Arizona. 

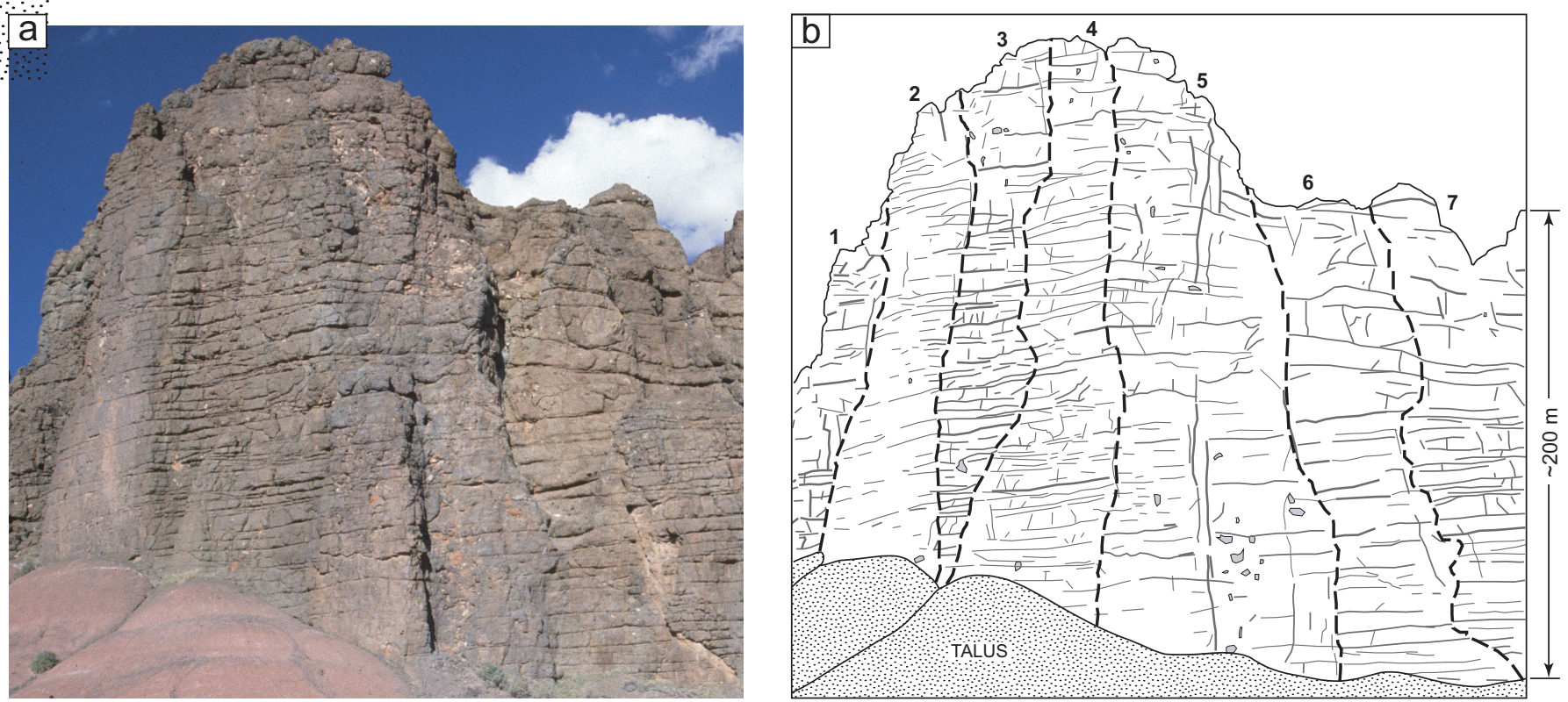

ROSS ET AL. (BV) FIG. 1 


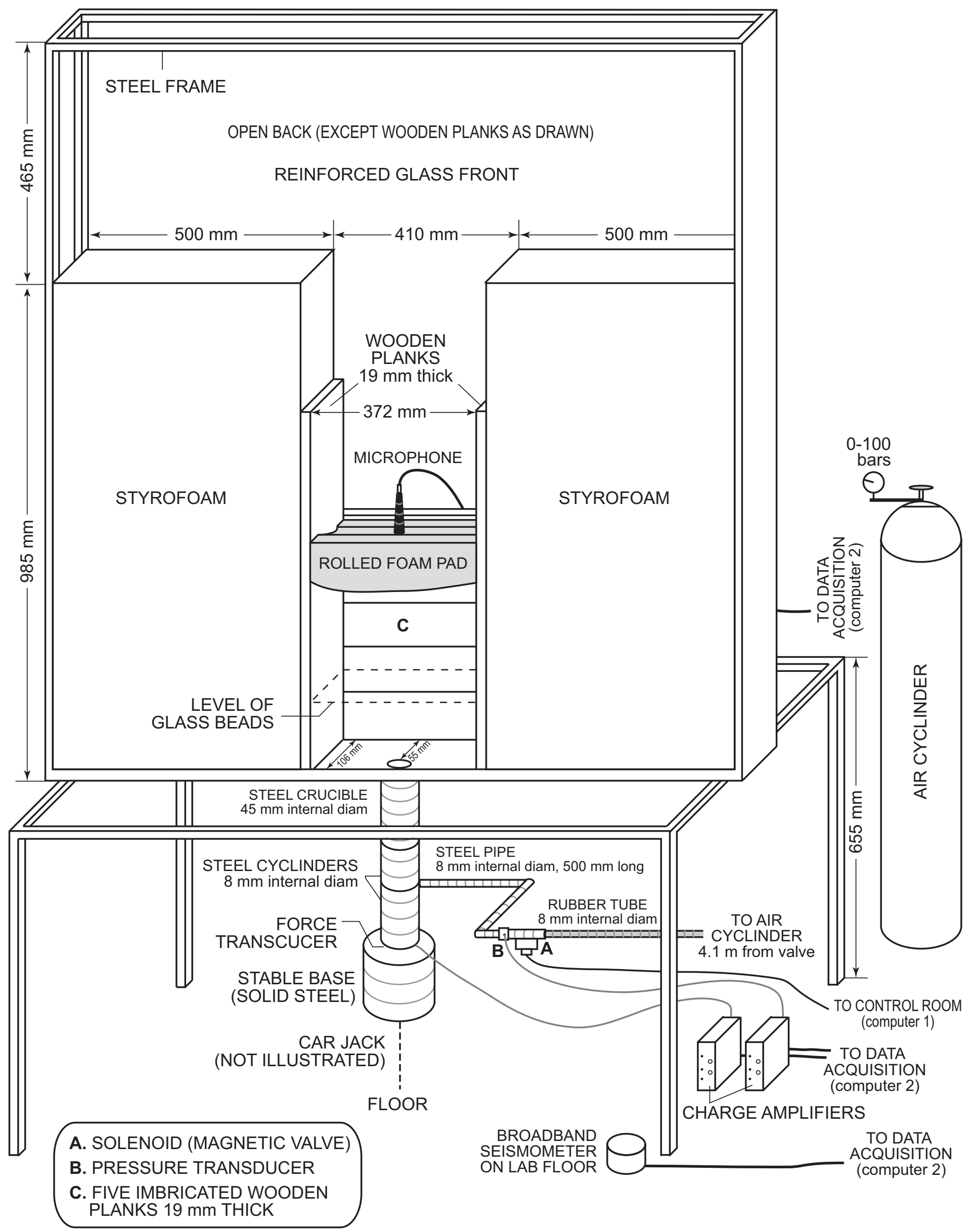

ROSS ET AL, BV, FIG. 2 

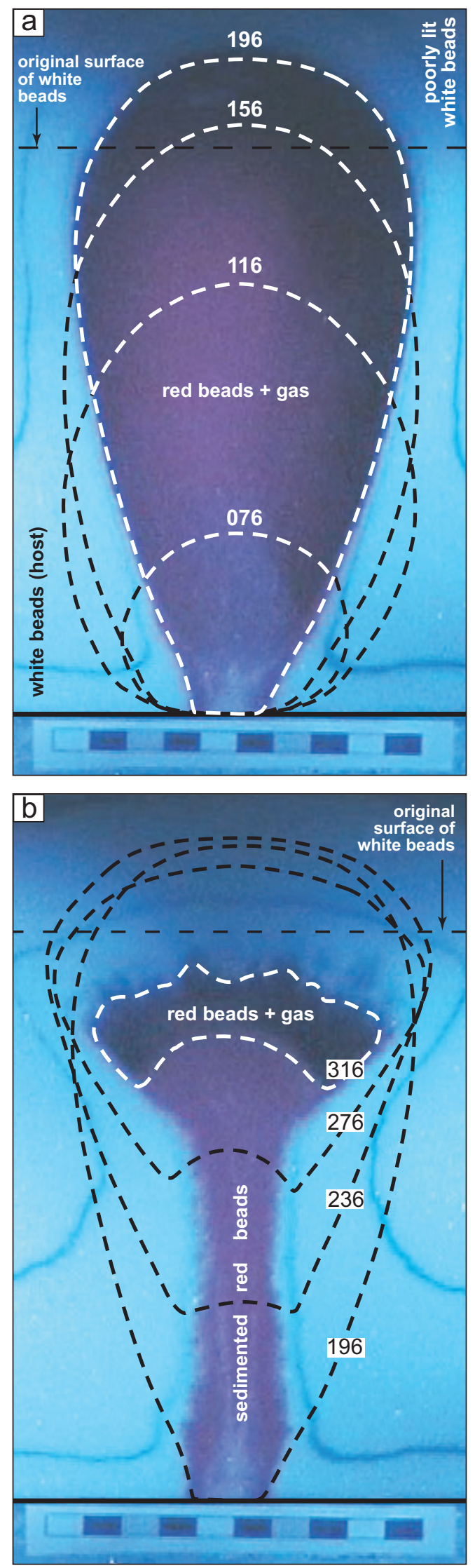

ROSS ET AL. (BV) FIG. 3 

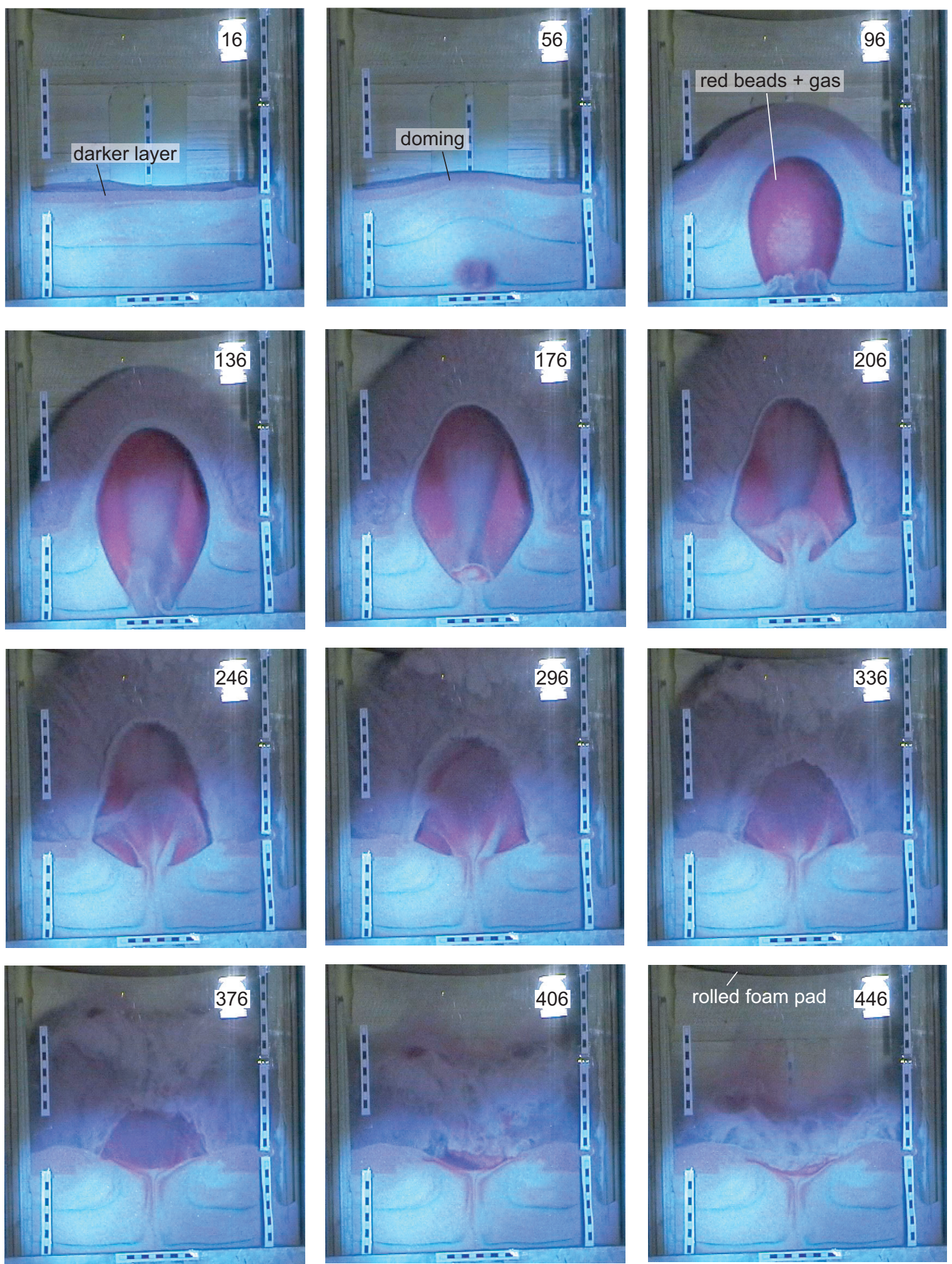

ROSS ET AL, BV, FIG. 4 


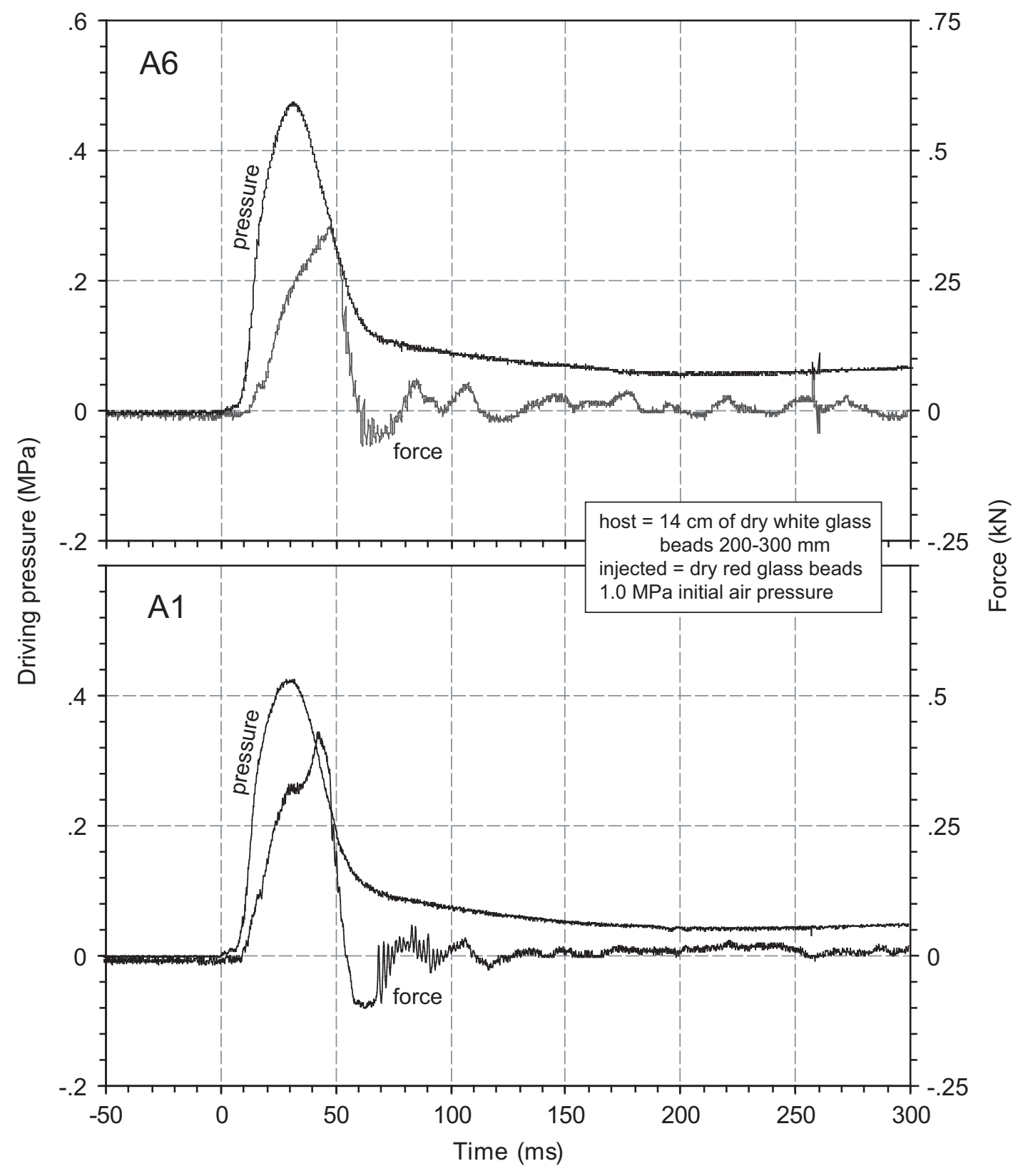

ROSS ET AL, BV, FIG. 5 
(Бәр) әбБие әшор unu!xeW

8 요 웅 응
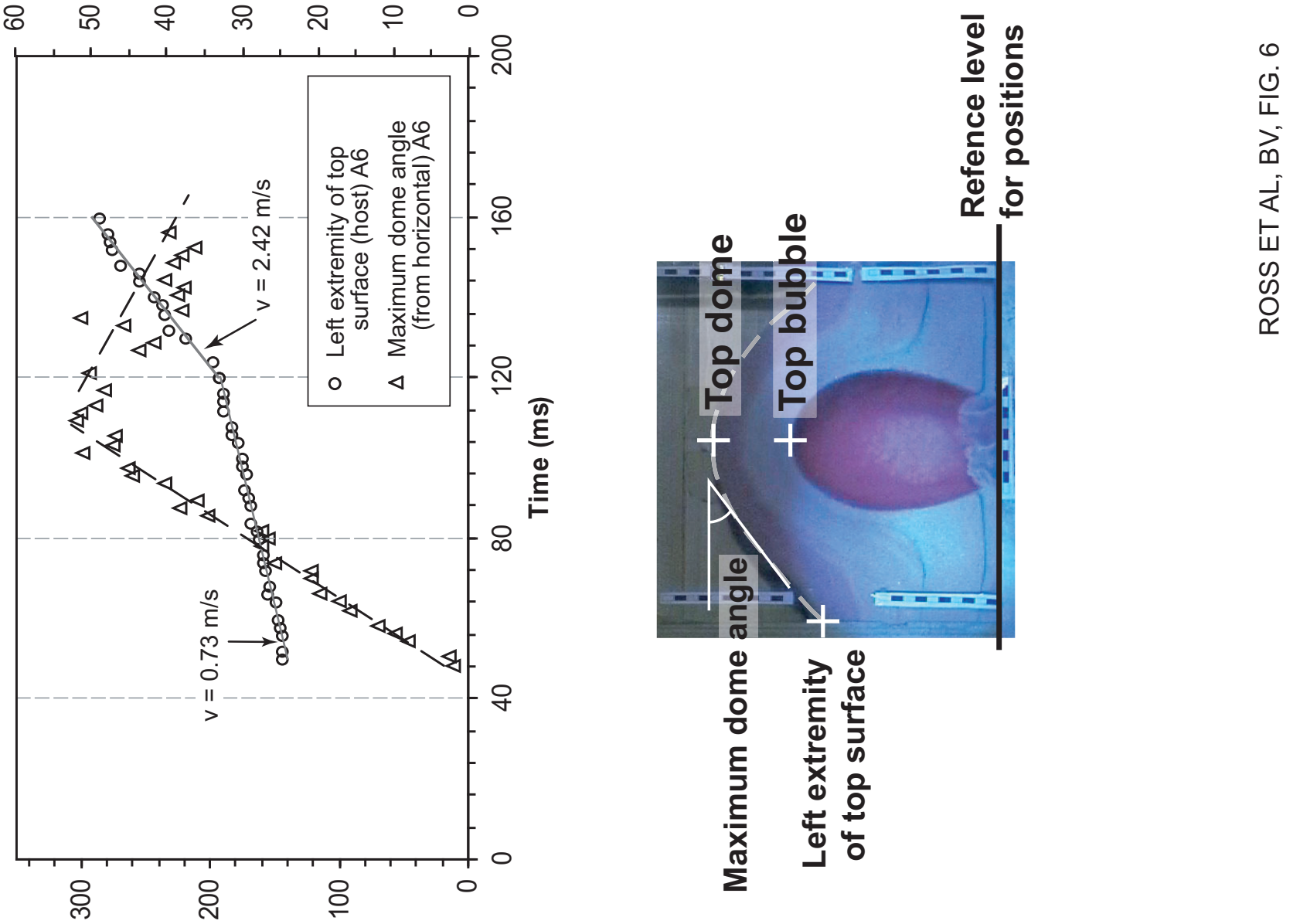

으 (mu) uo!!!sod ןอэ!น⿰^

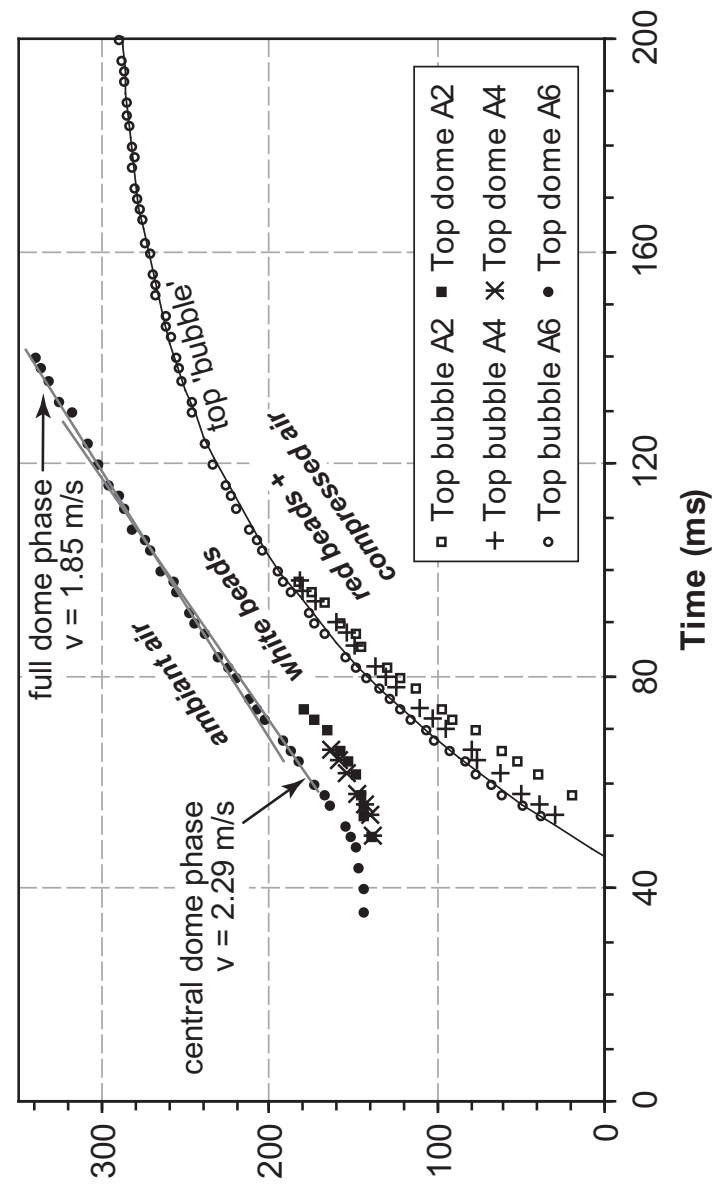

क

(um) uo!!!sod ןеग!มว $\Lambda$

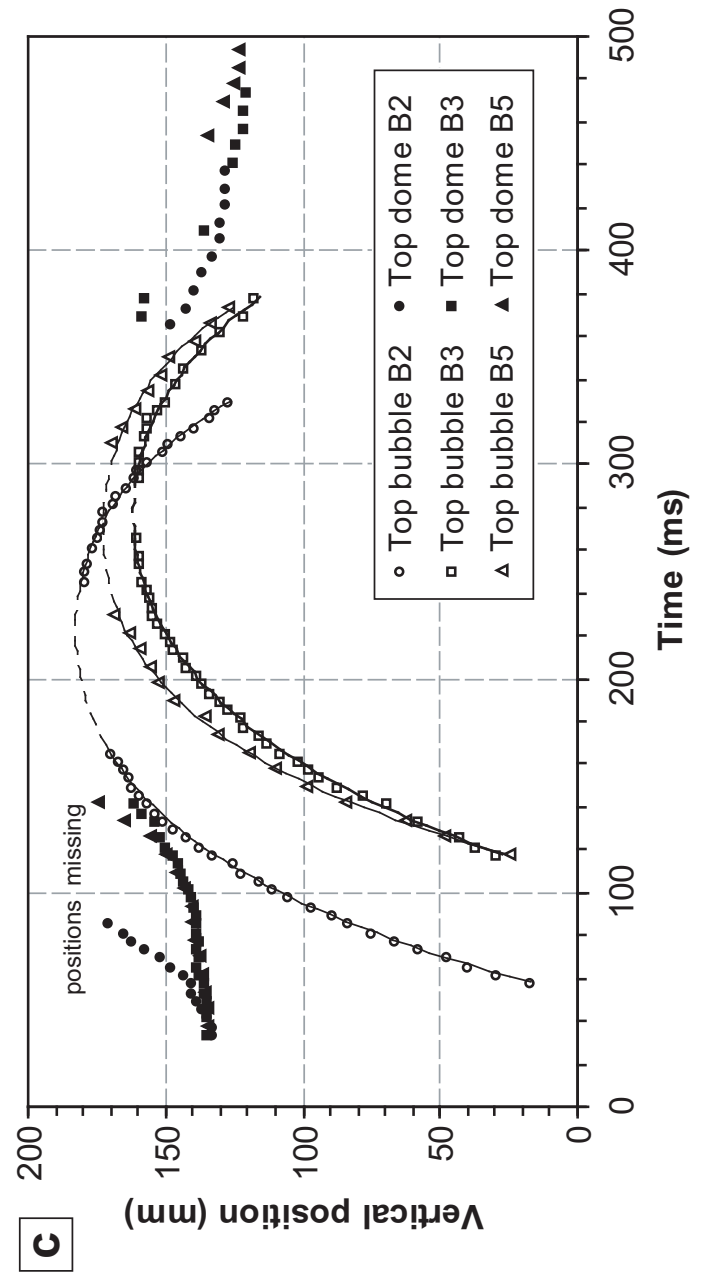




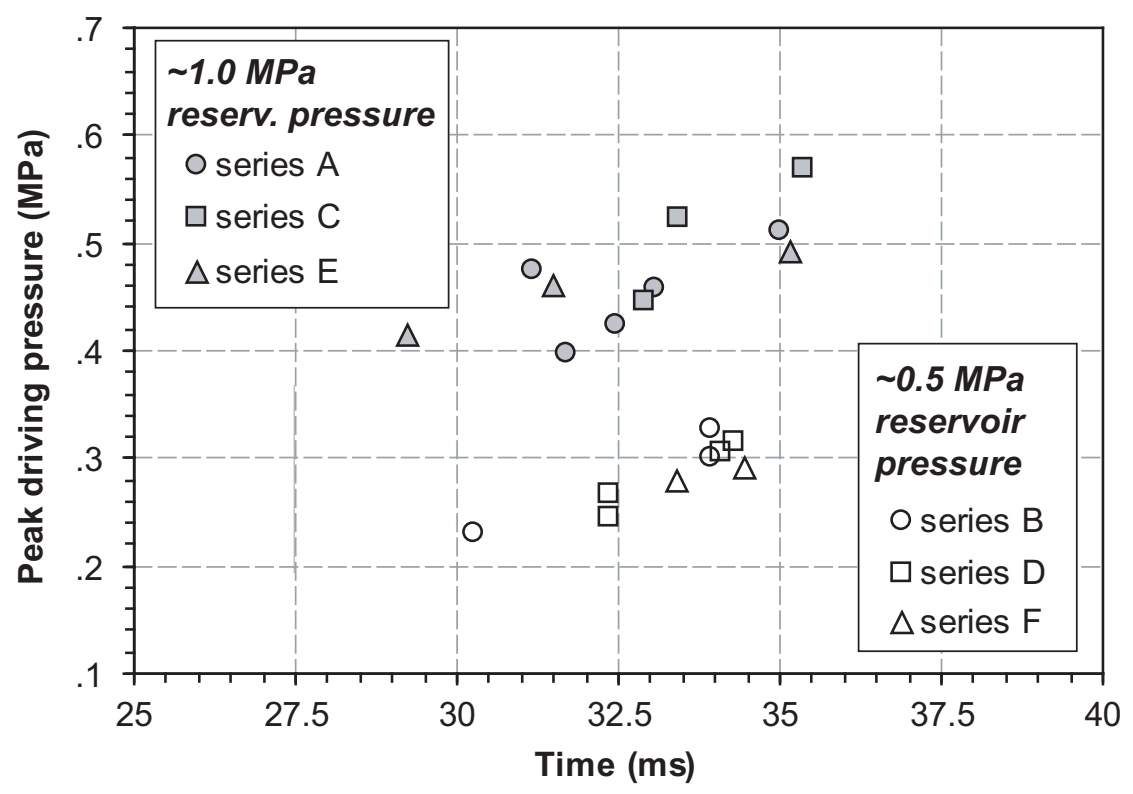

ROSS ET AL, BV, FIG. 7 

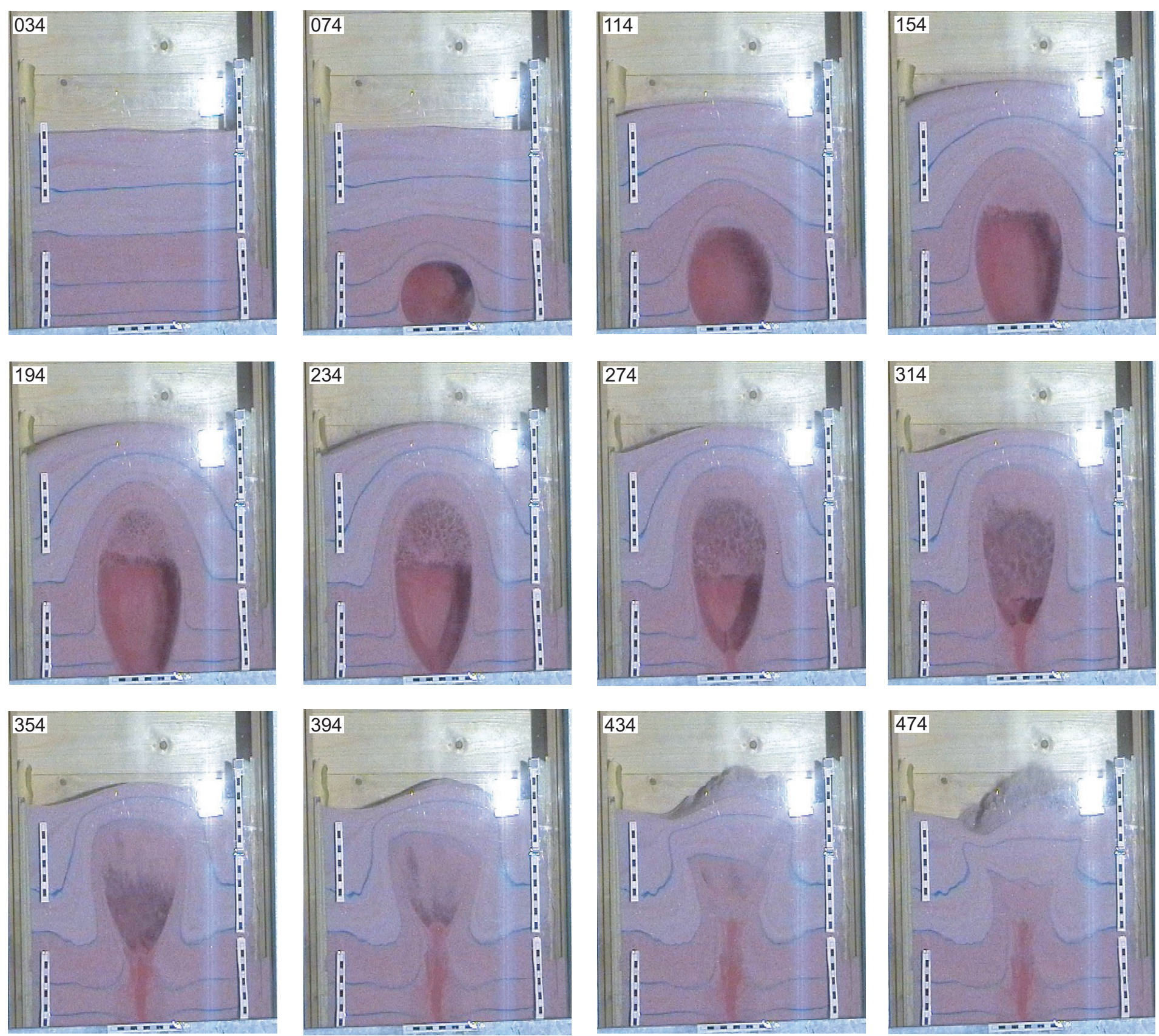

ROSS ET AL, BV, FIG. 8 


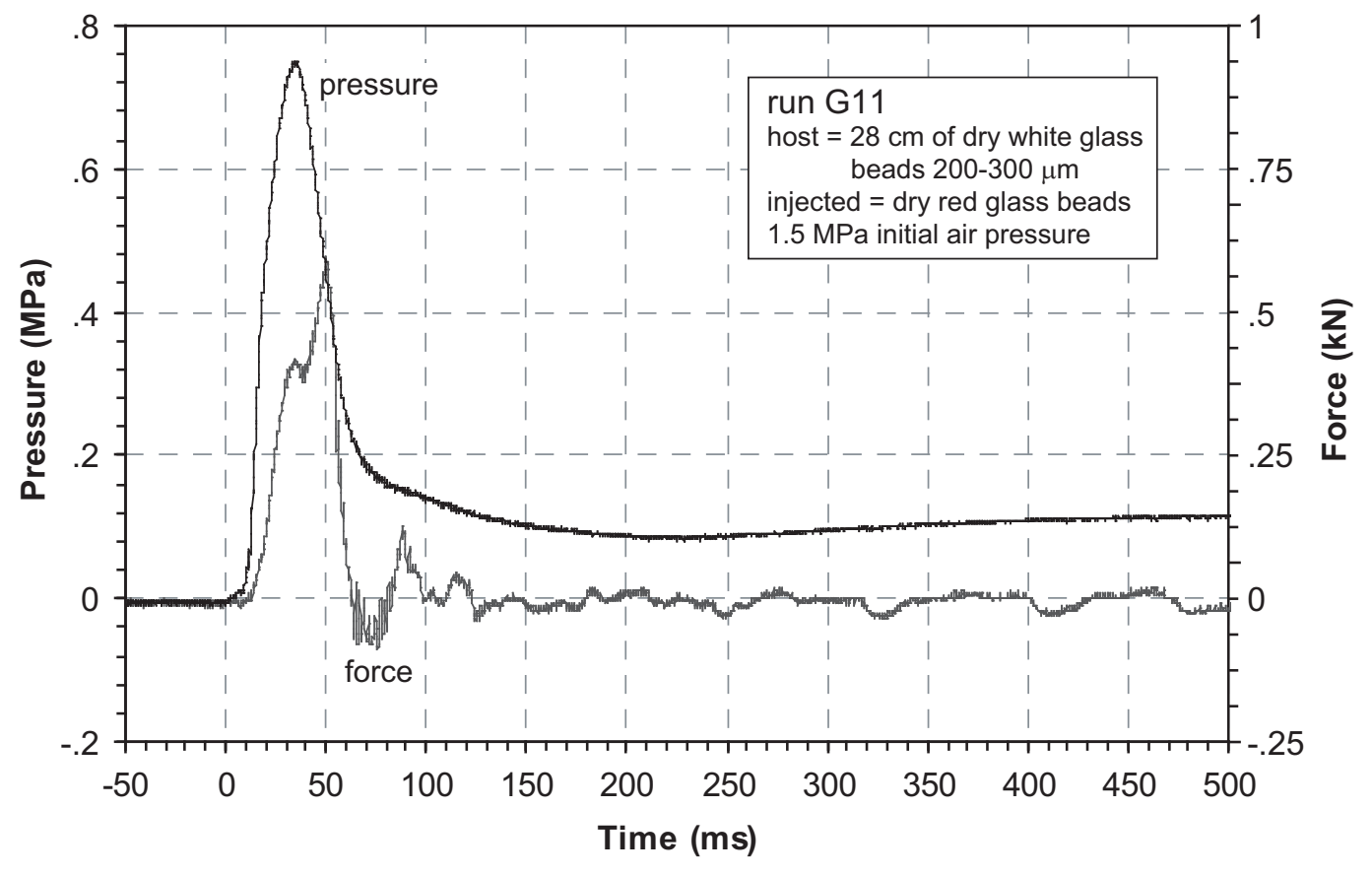

ROSS ET AL, BV, FIG. 9 

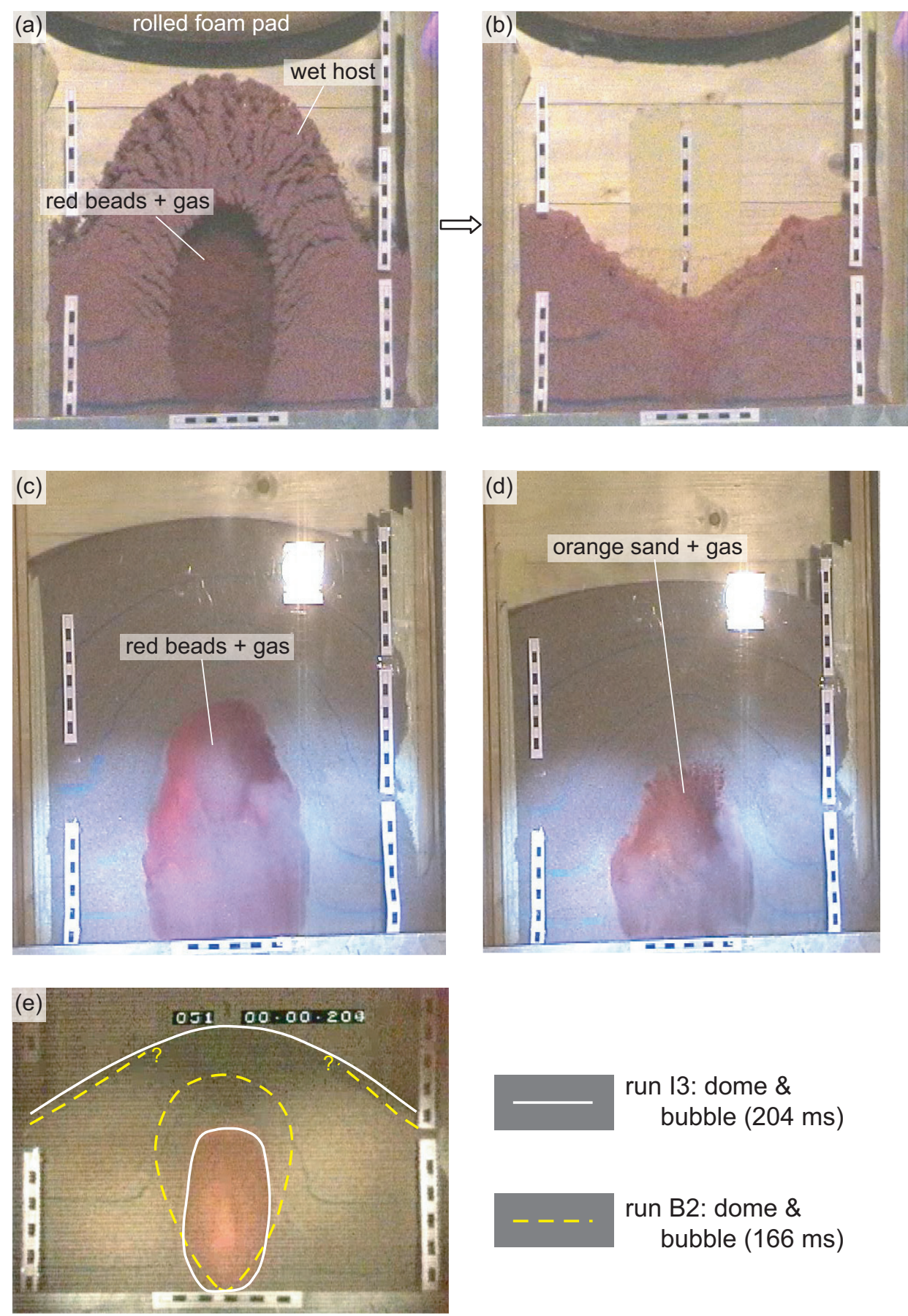

ROSS ET AL, BV, FIG. 10 

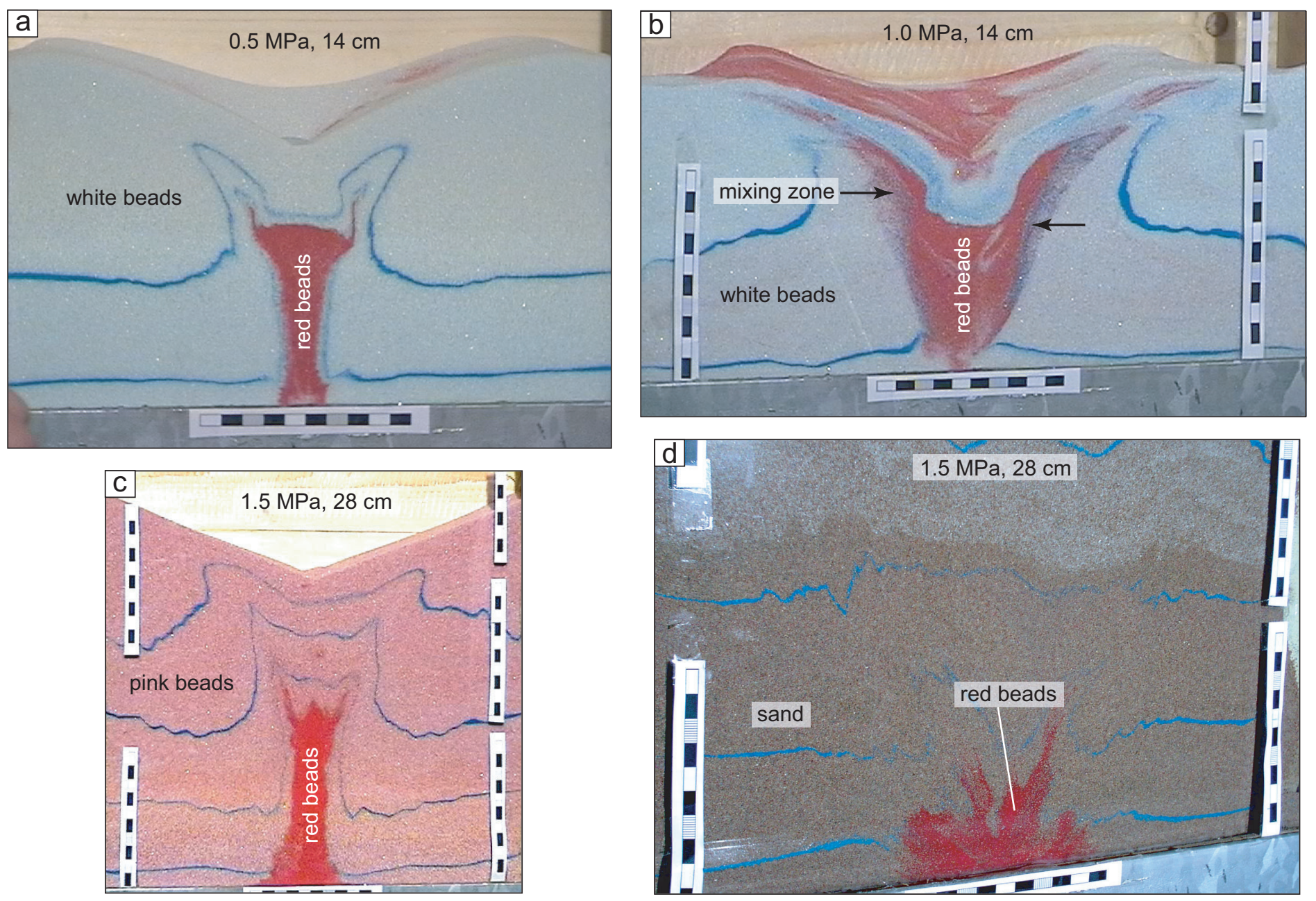

ROSS ET AL. (BV) FIG. 11 

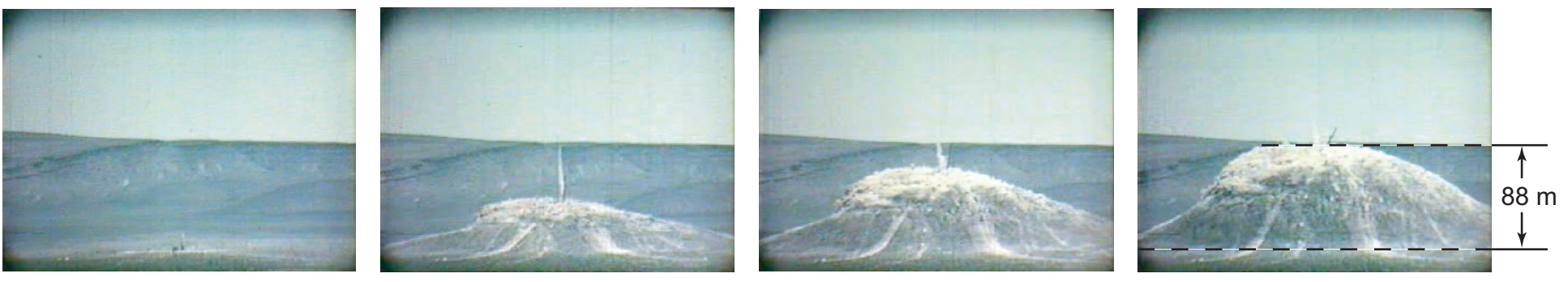

ROSS ET AL. (BV) FIG. 12 


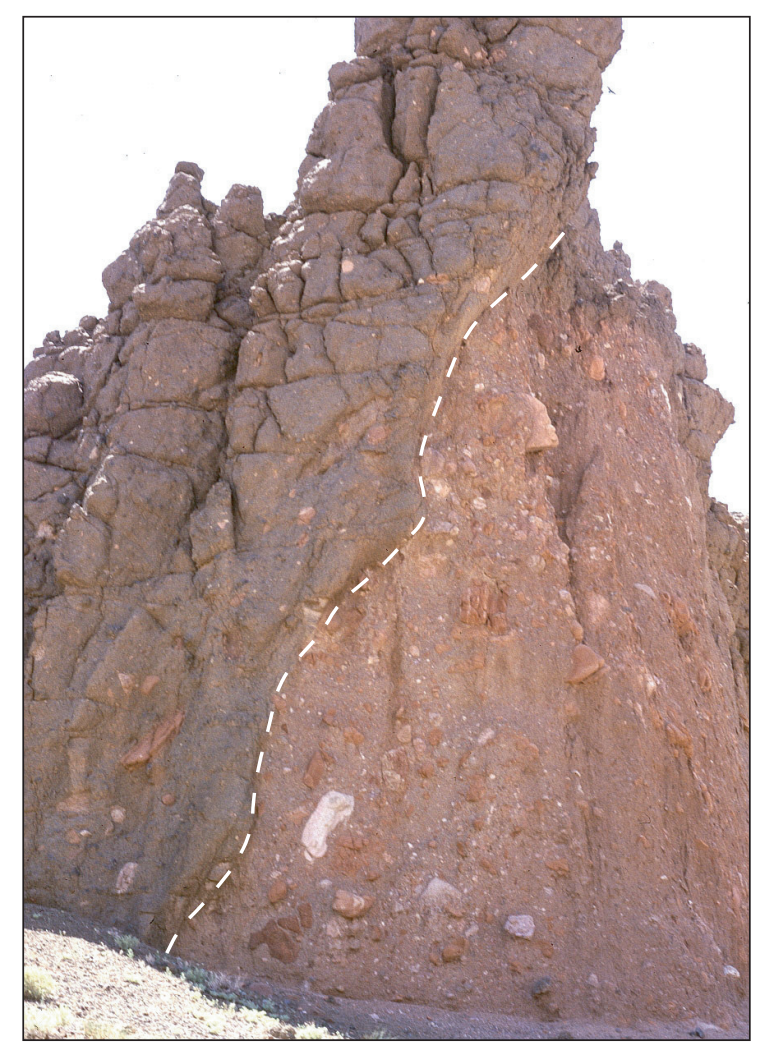

ROSS ET AL. (BV) FIG. 13 